\title{
Petrografía, geoquímica y geocronología U/Pb en circones de rocas ígneas y metamórficas a lo largo del Río Cuiarí en el sur del Departamento de Guainía, Colombia
}

\author{
Amed Bonilla $^{1 *}$; Thomas Cramer ${ }^{1,2}$; Marc Poujol ${ }^{3}$; Haroold Cano ${ }^{1}$; José Alejandro Franco ${ }^{1}$; Zeze Amaya ${ }^{1}$ \\ DOI: http://dx.doi.org/10.18273/revbol.v41n1-2019003 @ c c
}

Forma de citar: Bonilla, A., Cramer, T., Poujol, M., Cano, H., Franco, J.F., y Amaya, Z. (2019). Petrografía, geoquímica y geocronología $\mathrm{U} / \mathrm{Pb}$ en circones de rocas ígneas y metamórficas a lo largo del Río Cuiarí en el sur del Departamento de Guainía, Colombia. Boletín de Geología, 41(1), 55-84. DOI: 10.18273/revbol.v41n1-2019003.

\section{RESUMEN}

Para avanzar en la comprensión de la Provincia Geocronológica Rio Negro-Juruena (1,55-1,8 Ga) del Cratón Amazónico en el suroriente colombiano se analizaron rocas metamórficas, ígneas y meta-sedimentarias aflorantes alrededor del Río Cuiarí en el sur del Departamento de Guainía, zona limítrofe Colombia-Brasil. Con base en observaciones de campo, análisis mineralógicos, geoquímicos y edades LA-ICP-MS U/Pb en circones se identificó en el área un basamento Estateriano (formando aquí el Complejo Mitú) compuesto de granitoides tipo S, principalmente monzograníticos y en menor proporción cuarzo-monzoniticos a granodioriticos, calcoalcalinos, meta a peraluminosos, con características de granitos sin-colisiónales a pos-orogénicos con edades U/ $\mathrm{Pb}$ de cristalización entre 1760 y $1800 \mathrm{Ma}$. Adicionalmente afloran intrusivos graníticos más alcalinos de textura porfirítica con fenocristales ovoides de feldespato potásico y una edad de cristalización U/Pb en circones de $\sim 1750$ Ma (probablemente asociado a la Suite Intrusiva Tiquié definida en Brasil).

Sobre este basamento Estateriano fue depositada una secuencia sedimentaria (que pertenece al Grupo Tunuí) entre 1750 y 1600 Ma descritas como metarenitas y cuarcitas con turmalina, probablemente como miembro superior del Grupo Tunuí que fue afectado por metasomatismo relacionado con la intrusión de un granito porfirítico de dos micas con una edad de cristalización entre 1550 y 1600 Ma (asociado a la Suite Intrusiva Rio Içana). Circones heredados con edades del Complejo Mitú $\sim 1780$ Ma en este intrusivo sugieren un origen del magma por fusión parcial de material cratónico en presencia de suficiente agua y presión no demasiada alta para una temperatura de fusión relativamente baja que permitieron formar un magma enriquecido en fluidos y elementos incompatibles como Rb y K. Paragneises con edades en circones detríticos más jóvenes entre 1000-1800 Ma, cierran el ciclo geológico precámbrico reconocible en esta área de Colombia con un potencial mineralizante y desarrollo tectónico y paleogeográfico todavía por determinar en detalle.

Palabras clave: Complejo Mitú; Cratón Amazónico; Geocronología; U/Pb; Circón; Guainía.

\section{Petrography, geochemistry and zircon $\mathrm{U} / \mathrm{Pb}$ geochronology in igneous and metamorphic rocks, Cuiarí River, south of Guainía department, Colombia}

\footnotetext{
ABSTRACT

In order to archive a better understanding of the Rio Negro-Juruena Geochronological Province (1.55-1.8 Ga) of the Amazonian Craton in SE-Colombia, we performed analyses of metamorphic, igneous and metasedimentary rocks outcropping in vicinity of the Cuiarí-River in the south of Guainía Department, near the Brazilian border. Based on field observations, mineralogical, geochemical and U/Pb LA-ICP-MS analysis in zircons, we could identify in the study area a Statherian basement which forms the Mitú Complex. It is composed by

${ }^{1}$ Grupo de Estudios en Geología Económica y Mineralogía Aplicada (GEGEMA), Universidad Nacional de Colombia, Bogotá, Colombia. (*) abonillape@unal.edu.co, thcramer@unal.edu.co, hcanor@unal.edu.co, jafrancov@unal.edu.co, zamayap@unal.edu.co

${ }^{2}$ Departamento de Geociencias, Universidad Nacional de Colombia, Bogotá, Colombia.

${ }^{3}$ Geosciences Rennes, UMR CNRS 6118, Université de Rennes 1, OSUR, Campus de Beaulieu, Rennes, Francia. marc.poujol@univ-rennes1.fr
} 
S-type granitoides, mainly monzogranitic to a lesser amount of quartz-monzodioritic to granodioritic, with calc-alkalic meta to peraluminosos, syncollisional to post orogenic characteristics and with U/Pb crystallization ages between 1760 to $1800 \mathrm{Ma}$. Additionally, in the study area more alkalic granitic intrusions with ovoidal K-feldspar phenocrysts forming a porphyritic texture outcrop where $\mathrm{U} / \mathrm{Pb}$ zircon data suggest a crystallization age of $\sim 1750 \mathrm{Ma}$ (probably associated to the Tiquié Intrusion Suite defined in Brazil).

Over this Statherian basement, a sedimentary sequence (which may represent the Upper Member of the Tunuí Group in Brazil) was deposited some 1750-1600 Ma ago, where metarenites and quartzites were impregnated by tourmalines as a result of metasomatic processes related to the intrusion of a porphyritic two-mica granite crystalized 1550 to 1600 Ma ago (associated with the Rio Içana Intrusive Suite in Brazil). Some 1780 Ma old inherited zircons from the Mitú Complex in this intrusion suggest a magma origin by partial melting of cratonic cortical material triggered by sufficient water and low pressures for melting point decrease generating a magma enriched in fluids and incompatible elements like $\mathrm{Rb}$ and $\mathrm{K}$. Younger paragneisses with detrital zircon ages between 1000 to $1800 \mathrm{Ma}$ close the Precambrian geological cycle identified in this area of Colombia. Its mineralizing potential as well as a tectonic and paleogeographic history still to be deciphered in detail.

Keywords: Mitú Complex; Amazonian Craton; Geochronology; U/Pb; Zircon; Guainía.

\section{INTRODUCCIÓN}

El Departamento de Guainía forma parte de la Amazonía colombiana, que se extiende desde las estribaciones de la Cordillera Oriental andina por la gran región suramericana compartida por Venezuela, Brasil, Colombia, Ecuador, Perú, Guyana, Surinam, y Bolivia. La Amazonía de Colombia es la zona menos poblada y estudiada del país y una gran parte del conocimiento geológico sobre ella se sustenta sobre investigaciones realizadas en el noreste del Cratón Amazónico sobre todo en territorio de Brasil y Venezuela (e.g. Almeida et al., 1981; Almeida et al., 2007; Amaral, 1974; Bettencourt et al., 1999, 2010; Brito-Neves, 2011; Gansser, 1974; Gaudette y Olszewski, 1985; Pinheiro et al., 1976; Santos et al., 2003; Tassinari y Macambira 2004; Teixeira et al., 1989; Teixeira et al., 2010).

Debido a la cercanía y las estrechas relaciones entre el Departamento de Guainía y Brasil mencionamos primero algunos trabajos sobre la geología del país vecino; entre ellos Petri y Fulfaro (1983) describieron el Fanerozoico en Brasil, Almeida y Hasui (1984) el Precámbrico y Schobbenhaus et al. (1984) el desarrollo geológico en su conjunto. Desde pioneros como Katzer (1903) quien ya había descrito la región inferior del Amazonas y el conocimiento de hoy se dio un fuerte impulso para la investigación geocientífica en Brasil a partir de los años 70 del siglo pasado, cuando grandes inversiones en el programa RADAM (Radar en la Amazonía) permitieron generar mapas, informes y el descubrimiento de yacimientos minerales de clase mundial (e.g. Ministerio das Minas e Energia, 1983; Schobbenhaus et al., 1984). Estos resultados y estudios posteriores en Colombia a partir de un programa similar aunque más limitado (PRORADAM,
1979) empezaron a revelar una historia geológica compleja desde el Proterozoico, que como estamos reconociendo cada vez más en Colombia comprende una amplia variación de edades, composiciones y texturas, que dejaron sus huellas iniciales en rocas precámbricas metamórficas e ígneas como granitos calco-alcalinos, cuarcitas, gneises cuarzosos, gneises cuarzo-feldespáticos, granitos anorogénicos, sienitas nefelínicas, diques diabásicos, gabros, etc.

Un primer concepto fixista, inmovilístico (o autóctono) sobre el desarrollo del Cratón Amazónico, todavía influente entre los geólogos pioneros del país, asume la afectación de una masa continental estable formada en el Arqueano por procesos termales posteriores con retrabajamiento progresivo más joven hacia su periferia (Amaral, 1974; Costa y Hasui, 1997). Sin embargo, muchas evidencias permitieron establecer que el cratón se formó más por procesos de aglomeración, amalgamación o acreción de arcos (Condie, 2005; Geraldes et al., 2001) de material más joven alrededor de núcleos más antiguos relacionado con la dinámica de tectónica de placas, iniciada posiblemente desde hace más de 3,5 Ga hasta 1,0 Ga (Domeier y Torsvik, 2014; Ernst, 2017; Greber et al., 2017; Stern, 2005; Stern et al., 2016) y procesos de subducción o acreción de corteza oceánica antes y después de la formación de supercontinentes como primero Columbia (Meert y Santosh, 2017; Rogers y Santosh, 2002), después Rodinia (McMenamin y McMenamin, 1990; Piper, 2000) y Pangea con ciclos de Wilson asociados (Wilson, 1966), la influencia de plumas mantélicas (Hill, 1993; Yuen et al., 2007) y otros factores induciendo rifting continental. Este modelo movilístico (alóctono) compartido por la mayoría de los investigadores en el tema y sostenido por muchos datos geocronológicos 
asigna a la parte colombiana del Cratón Amazónico edades mesoproterozoicas de 1,78 Ga hasta 1,1 Ga (Priem et al., 1982; Ibañez, 2011; Bonilla et al., 2016; Cordani et al., 2016) mientras los núcleos más antiguos encontrados hasta ahora en Venezuela oriental y Surinam $(>3,4 \mathrm{Ga} \mathrm{U} / \mathrm{Pb}$ y $\mathrm{Rb} / \mathrm{Sr})$ son granulitas y gneises intercalados con hierro bandeado del Complejo Imataca (Montgomery y Hurley, 1978), separados de rocas más jóvenes (proterozoicas) por contacto tectónico.

Como aporte para un mejor entendimiento de las relaciones estratigráficas del Complejo Mitú (Galvis et al., 1979; López et al., 2007) y la evolución del oriente colombiano presentamos en este trabajo nuevos datos petrográficos, geoquímicos y geocronológicos U/ $\mathrm{Pb}$ en circones de rocas proterozoicas aflorantes a lo largo del Río Cuiarí entre las comunidades de Campo Alegre y Miraflores, y la parte alta de Caño Naquén al sur del Departamento del Guainía, en la zona limítrofe Colombia-Brasil, lo que permite también una mejor correlación con las unidades descritas en el país vecino, Brasil.

\section{ANTECEDENTES}

La franja colombiana del basamento precámbrico en el Departamento de Guainía fue descrita primero como Grupo Basamento (Gansser, 1954), después Complejo Guayanés (Pinheiro et al., 1976), en seguida como Complejo Migmatítico de Mitú (Galvis et al., 1979) y últimamente como Complejo Mitú (López et al., 2007) con escasos afloramientos estudiados entre el Río Guaviare al norte, el Río Caquetá al sur, y la Serranía de Chiribiquete al occidente (FIGURA 1). De esta área aproximada de $88.000 \mathrm{~km}^{2}$ cuya extensión ha sido inferida inicialmente con base en interpretación geofísica hasta 2012 solamente se tenía cartografía sistemática de unos $1.200 \mathrm{~km}^{2}$, o sea el 1,4\% (López, 2012) y también hoy sus relaciones no se han definido con claridad (INGEOMINAS, 2006; Servicio Geológico Colombiano, 2015). Por eso Rodríguez (2012) tiene razón cuando insiste durante un debate (López, 2012; Rodríguez, 2012; Rodríguez et al., 2011) que todavía falta mucha información como para definir toda esta área con un nombre definitivo y seguramente surgirán divisiones más detalladas, como está ocurriendo de manera avanzada en Brasil; para el Complejo Migmatítico de Mitú (denominación en la cual insisten Rodríguez et al., 2011 y Rodríguez, 2012) se han propuesto hasta el momento las unidades Monzogranito de Mitú, Granofels de Pringamosa, Neis del Yi en la Plancha 443 Mitú (Rodríguez et al., 2011) y el Granito Rapakivi de Matraca (Bonilla et al., 2016).

Sobre lo que no hay duda es que estas rocas forman parte del Escudo de Guayana con edades precámbricas (Priem et al., 1982; Ibañez, 2011; Bonilla et al., 2016; Cordani et al., 2016) y se correlacionan en su parte meridional con el Complejo Cumati en Brasil con una edad 1,74 Ga (Almeida et al., 2007). Estas unidades están enmarcadas dentro de la Provincia Geocronológica Rio Negro - Juruena formada hace 1,8-1,55 Ga (Tassinari y Macambira, 1999; Teixeira et al., 1989) con gneises graníticos y granitoides de composiciones granodioríticas y tonalíticas o según Santos et al. (2000) como la Provincia de Rio Negro (1,82-1,52 Ga) con rocas metamórficas e ígneas graníticas que están foliadas o bandeadas y que son intruídas por cuerpos graníticos de diferentes afinidades.

Maya-Sánchez (2001) resumió el conocimiento hasta este momento del basamento localizado al sur del Río Guaviare hasta el Río Pira-Paraná (Bruneton et al., 1983; Galvis et al., 1979) como rocas metamórficas compuestas principalmente por rocas graníticas de origen anatéctico asociadas a gneises migmatíticos con biotita y silicatos de aluminio, desde la facies anfibolita alta hasta el dominio anatéctico $\left(\mathrm{T}=600\right.$ a $750^{\circ} \mathrm{C}, \mathrm{p}=2-5$ kb). Para una muestra Rodríguez et al. (2011) reportan hipersteno en paragénesis con cuarzo, plagioclasa, feldespato potásico y biotita, indicativos de las facies granulita, con temperaturas sobre los $800^{\circ} \mathrm{C}$.

Recientemente, Cordani et al. (2016) avanzaron aún más y con base en la recopilación de estudios anteriores (Barrios et al., 1985; Gaudette y Olszewski, 1985; Priem et al., 1982) y nuevos datos geocronológicos proponen hacia el nororiente del Departamento de Guainía diferenciar un Cinturón Atabapo metamórfico (FIGURA 1) formado por una serie de pulsos orogénicos durante el Paleoproterozoico (Estateriano) hace 18001740 Ma (como parte del Complejo Mitú) que fue intruído por rocas graníticas hace unos $1500 \mathrm{Ma}$. La integración del análisis de 27 muestras granitoides tomadas por Priem et al. (1982), Pinheiro et al. (1976) y Santos et al. (2003) entre Mitú, en Colombia, y Iauaretê, en Brasil, y de muestras otorgadas por el Servicio Geológico Colombiano llevaron a Cordani et al. (2016) a diferenciar otro cinturón más joven llamado Cinturón de Vaupés de 1580-1520 Ma al suroccidente (FIGURA 1), en donde interpretan rocas con edades de $\sim 1750$ Ma como ventanas del basamento, mientras las rocas graníticas más jóvenes no deformadas representarían magmatismo granítico post-tectónico. 


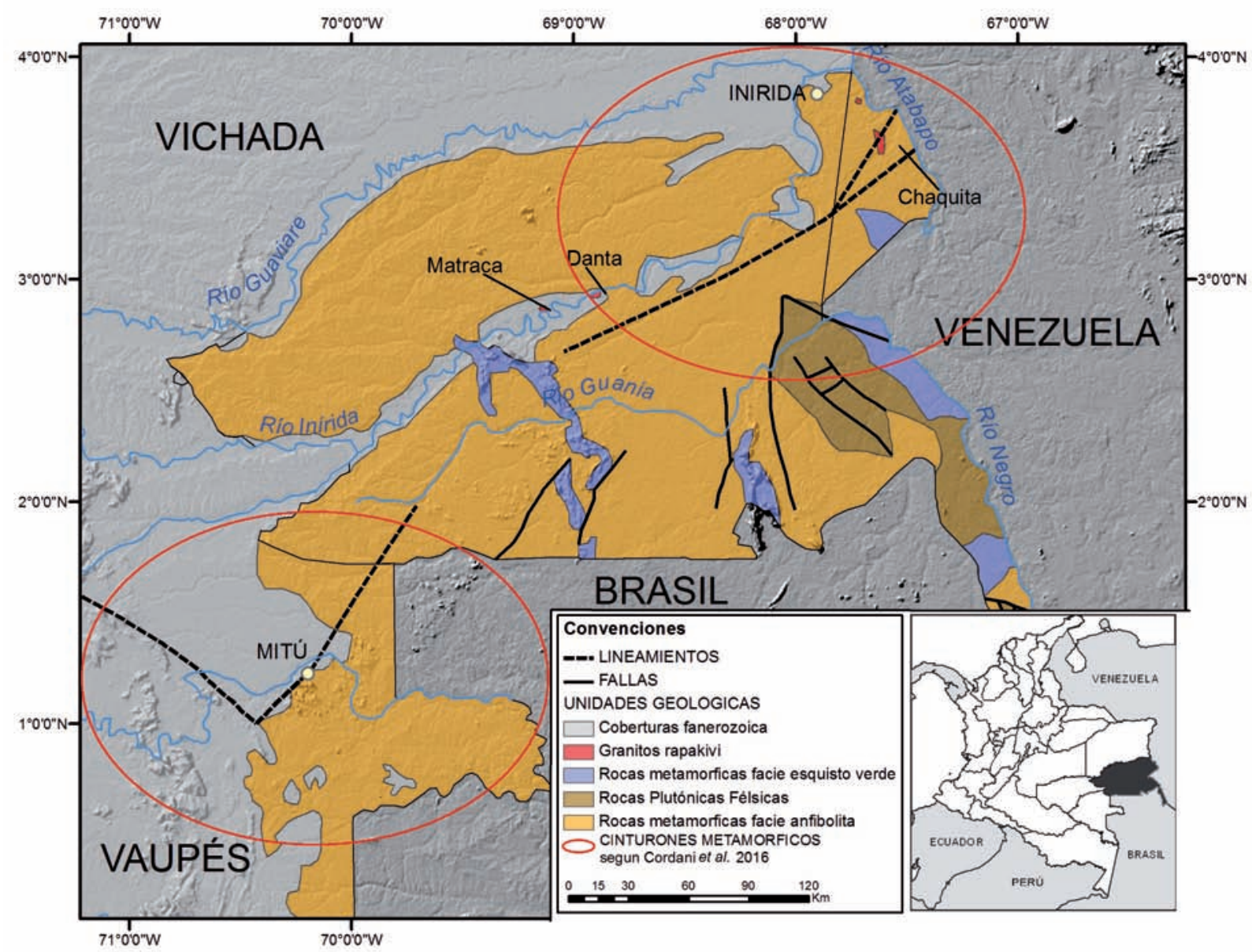

FIGURA 1. Mapa del Complejo Mitú (modificado de Bonilla et al., 2016; López et al., 2007) y localización del cinturón nororiental "Cinturón Atabapo" y cinturón suroccidental "Cinturón Vaupés", modificado de Cordani et al. (2016).

La edad más antigua en la región fue reportada en la parte venezolana del Granito de Atabapo con una isócrona $\mathrm{Rb}-\mathrm{Sr}$ de $2000 \mathrm{Ma}$ (Gaudette et al., 1978). En Colombia, Priem et al. (1982) obtuvieron varias dataciones sobre granitos y gneises en un rango de 1780 Ma hasta $1251 \mathrm{Ma}$. El dato de 1780 Ma por isócrona $\mathrm{Rb}$-Sr en roca total sobre el Granito de San Felipe fue interpretado como resultado del enfriamiento al finalizar el Evento Transamazónico, mientras que las edades más recientes marcarían tanto recalentamientos durante el evento magmático Pargüense con edades por isócronas $\mathrm{Rb}-\mathrm{Sr}$ entre $1575 \mathrm{Ma}$ y $1450 \mathrm{Ma}$, así como un rejuvenecimiento isotópico durante el evento Nickeriense con siete resultados $\mathrm{Rb}-\mathrm{Sr}$ y $\mathrm{K}-\mathrm{Ar}$ entre $1392 \mathrm{Ma}$ y $1261 \mathrm{Ma}$ (Toussaint, 1993). Rodríguez et al. (2011) reportaron dataciones $\mathrm{Ar}$ - Ar a partir de biotita en el Monzogranito de Mitú de una edad plateau de $1312,7 \pm 10,8$ Ma y una edad plateau intermedia de $1276,1 \pm 10,6$ Ma y para el Neis del Caño Yi una edad plateau de $1310,7 \pm 10,5$ Ma y una edad plateau intermedia de $1245,0 \pm 10,2 \mathrm{Ma}$, lo que igualmente asocian con el evento Nickeriense.

La mayor parte del basamento cristalino se encuentra cubierta por sedimentos cenozoicos, así como por un espeso bosque tropical que componen un gran paisaje de peneplanicies modeladas por meteorización tropical fuerte y ríos meándricos en extensas llanuras aluviales, lo que dificulta su estudio. Sin embargo, en el Departamento de Guainía también se encuentran rocas estratificadas sedimentarias del Proterozoico con bajo grado de metamorfismo que sobresalen como serranías de la extensa llanura selvática y que se extienden desde Colombia hacia Brasil (e.g. Caranacoa y Naquén). Son constituidas principalmente por areniscas, areniscas conglomeráticas, cuarcitas, metaconglomerados, filitas y lodolitas. A nivel regional son designadas como una unidad afín a Roraima (Gansser, 1974; Ghosh, 1985) plegada y metamorfoseada (Santos et al., 2003). Fueron definidas en Brasil como Grupo Tunuí, pero 
en Colombia se le conoce como Formación Maimachi (González-Iregui, 1989; Renzoni, 1989a), Formación La Pedrera (Galvis, 1993) o Formación Caranacoa y se les atribuye una edad de depositación de 1,55-1,81 Ga (Santos et al., 2003).

\section{METODOLOGÍA}

\section{Trabajo de campo y toma de muestras}

Durante una salida de campo en el año 2015 y una segunda salida en el año 2017 - en época de verano (diciembrefebrero) cuando gracias a un nivel de los ríos más bajo afloran más rocas - se hicieron recorridos y un muestreo sistemático en 25 estaciones de los afloramientos observados a lo largo del Río Cuiarí (afluente del Rio Içana) y la parte alta de Caño Naquén (afluente del Rio Guainía) en distancias de 80 y 20 km respectivamente (FIGURA 2). En cada estación se registraron datos como litología, textura, estructura y relaciones de campo. Se midió la radioactividad en diferentes puntos de cada afloramiento con un equipo Inspector Alert en microsievert/hora $(\mu \mathrm{Sv} / \mathrm{h})$, después de calibrar al aire. En las zonas menos afectadas por meteorización u otra contaminación, distinguiendo roca homogénea, venas, diques y variaciones texturales de interés, se tomaron mínimo $1 \mathrm{~kg}$ de muestra que se guardaron en bolsas de plástico debidamente rotuladas y cerradas. Los códigos de las muestras se asignaron según la Plancha 403 o 404 que cubren el área de estudio.

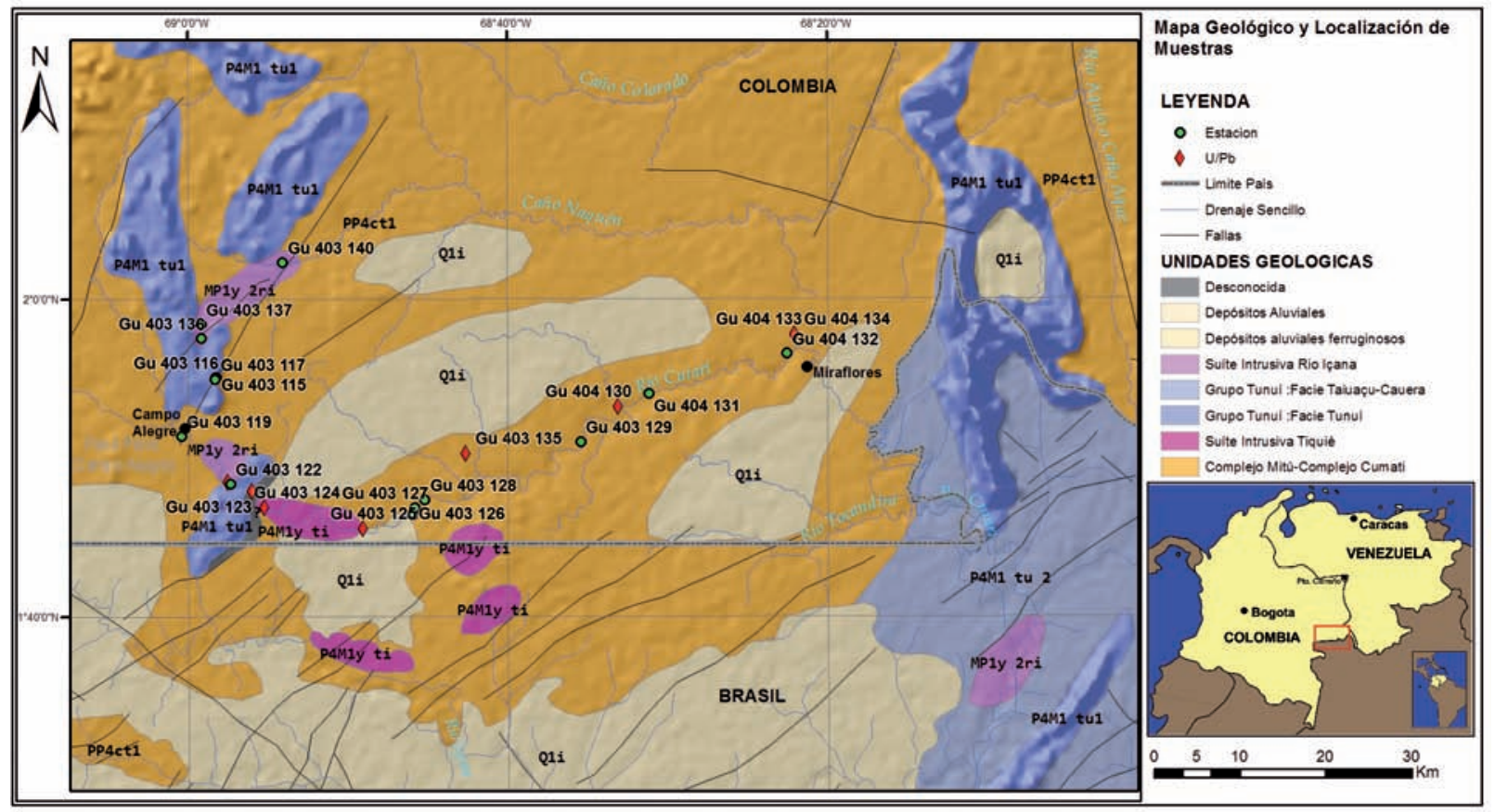

FIGURA 2. Estaciones y toma de muestras a lo largo del Río Cuiarí y parte alta de Caño Naquén (TABLA 1) indicados en el mapa geológico, modificado de Almeida et al. (2004) y del Servicio Geológico Colombiano (2015). Círculos verdes representan estaciones generales y trapezoides rojos estaciones donde se realizaron dataciones $\mathrm{U} / \mathrm{Pb}$ en este estudio.

\section{Petrografía y geoquímica}

De los 25 afloramientos visitados y muestreados se escogieron para esta investigación las rocas más representativas de cada unidad litoestratigráfica aflorante en el Río Cuiarí y la parte alta de Caño Naquén, con poca alteración visible, aptas para análisis petrológico, geoquímico y geocronológico. Las secciones delgadas fueron analizadas en un microscopio petrográfico Zeiss Axio Scope A1. La clasificación petrográfica modal de rocas ígneas se efectuó a partir de conteo por 300 puntos, según las recomendaciones de la IUGS (Gillespie y
Styles, 1999; Maitre et al., 2002; Streckeisen, 1978). Para determinar los elementos mayores, menores y traza (TABLA 1), 10 muestras (de las cuales 8 fueron usadas también para geocronología, TABLA 2) fueron pulverizadas, mezcladas y prensadas con cera espectrométrica Merck en relación muestra:cera de 10:1 y analizadas con un equipo de fluorescencia de rayos X, Phillips MagixPro PW - 2440, en la Universidad Nacional de Colombia, Sede Bogotá (tubo de rodio, potencia máxima de $4 \mathrm{~kW}$, límite de detección de elementos pesados metálicos 20 ppm). Los datos 
geoquímicos fueron procesados en una tabla Excel y Complejo Mitú por Bruneton et al. (1983) y la amplia el software libre GCDkit5.0 (Janoušek et al., 2006). base de datos geoquímicos mundial de EarthChem.org Donde se compararon los resultados petrográficos- (www.earthchemportal.org). geoquímicos con datos obtenidos en granitoídes del

TABLA 1. Geoquímica de las muestras analizadas (óxidos de elementos mayores en \% y elementos traza en ppm, <ld: por debajo del límite de detección de 20 ppm del equipo FRX).

\begin{tabular}{|c|c|c|c|c|c|c|c|c|c|c|}
\hline \multirow{2}{*}{$\begin{array}{c}\text { UNIDAD } \\
\text { Muestra }\end{array}$} & \multicolumn{4}{|c|}{ Complejo Mitú } & \multicolumn{2}{|c|}{ Suite Intrusiva Rio Içana } & \multicolumn{2}{|c|}{ Suite Intrusiva Tiquié } & \multicolumn{2}{|c|}{ Desconocida } \\
\hline & GU-403-135-B & $\begin{array}{c}\text { GU-403- } \\
135-A\end{array}$ & GU-404-134 & GU-404-130 & GU-404-133 & GU-403-121 & GU-403-124 & GU-403-125 & GU-403-123-A & $\begin{array}{c}\text { GU-403- } \\
123-\mathrm{B}\end{array}$ \\
\hline Roca & $\begin{array}{l}\text { granodiorita } \\
\text { gruesa, } \\
\text { inequigranular }\end{array}$ & $\begin{array}{c}\text { qz- } \\
\text { monzodiorita }\end{array}$ & monzogranito & granodiorita & $\begin{array}{c}\text { qz- } \\
\text { monzodiorita }\end{array}$ & $\begin{array}{l}\text { granito de } \\
\text { dos micas } \\
\text { (biotita y } \\
\text { muscovita) }\end{array}$ & $\begin{array}{c}\text { monzo- } \\
\text { sienogranito } \\
\text { porfirítica, } \\
\text { fspK } \\
\text { ovoides sin } \\
\text { orientación }\end{array}$ & & $\begin{array}{c}\text { paragneis con } \\
\text { bandeamiento } \\
\text { en dirección } \\
\mathrm{S} 61 \mathrm{~W} / 68 \mathrm{SE} \text {, }\end{array}$ & \\
\hline Petrografía & $\begin{array}{l}\text { Qz } 47 \%, \mathrm{Pl} \\
24 \% \text { Fsp } 9 \% \text {, } \\
\text { Bt } 12 \% \text {, Ms } \\
3 \% \text {, circón y } \\
\text { opacos. }\end{array}$ & $\begin{array}{c}\text { Qz 7\%, Pl } \\
\text { 30\% Fsp } \\
\text { 16\%, Bt 18\%, } \\
\text { hbl 15\%, } \\
\text { circón titanita } \\
\text { 9\%. }\end{array}$ & $\begin{array}{l}\text { Qz } 42 \% \text {, Pl } \\
24 \% \text {, Fsp } \\
27 \% \text {, Bt } 3 \%\end{array}$ & $\begin{array}{l}\text { Qz, Pl, Fsp, } \\
\text { Bt, Ep y Spn }\end{array}$ & $\begin{array}{l}\text { Qz, Fsp, Pl, } \\
\text { Bt cloritizada, } \\
\text { Ep y Spn }\end{array}$ & $\begin{array}{c}\text { Qz } 35 \%, \\
\text { Fsp 30\%, } \\
\text { Plg16\%, Bt } \\
8 \% \text { y Ms } 8 \%\end{array}$ & $\begin{array}{c}\text { Qz 21\%, } \\
\text { Fsp 43\%, Pl } \\
21 \%, \text { Bt } 8 \% \\
\text { y Ms 2\% }\end{array}$ & & $\begin{array}{l}\text { Ms, Bt, Qz, Fsp } \\
\text { y circones }\end{array}$ & \\
\hline $\begin{array}{c}\text { Rad. campo } \\
\mu \mathrm{Sv} / \mathrm{h}\end{array}$ & & & 0,26 & 0,4 & 0,4 & 0,6 & & 0,72 & & \\
\hline $\begin{array}{l}\text { Rad- Placa } \\
\text { sec. delg. } \\
\mu \mathrm{Sv} / \mathrm{h}\end{array}$ & 0,31 & 0,31 & 0,4 & & & & & & 0,35 & \\
\hline $\mathrm{SiO}_{2}$ & 72,00 & 54,12 & 73,46 & 63,77 & 53,61 & 69,52 & 67,82 & 68,37 & 68,00 & 80,63 \\
\hline $\mathrm{Al}_{2} \mathrm{O}_{3}$ & 12,29 & 17,43 & 12,34 & 13,35 & 16,10 & 16,84 & 14,32 & 22,62 & 17,02 & 9,44 \\
\hline $\mathrm{Fe}_{2} \mathrm{O}_{3} \mathrm{t}$ & 7,42 & 11,98 & 5,11 & 8,89 & 15,59 & 3,26 & 7,10 & 2,52 & 7,71 & 6,11 \\
\hline MnO & 0,05 & 0,29 & 0,05 & 0,17 & 0,22 & 0,06 & 0,10 & 0,04 & - & 0,04 \\
\hline MgO & 0,77 & 1,48 & 0,25 & 2,03 & 1,95 & 0,21 & 0,51 & - & 0,39 & 0,63 \\
\hline $\mathrm{CaO}$ & 1,31 & 7,76 & 1,51 & 4,17 & 6,00 & 1,67 & 1,81 & 0,27 & - & 0,03 \\
\hline $\mathrm{Na}_{2} \mathrm{O}$ & 1,76 & 1,40 & 1,32 & 1,14 & 1,58 & 1,40 & 1,12 & 0,32 & - & - \\
\hline $\mathbf{K}_{2} \mathbf{O}$ & 2,81 & 2,30 & 5,38 & 5,19 & 2,20 & 6,00 & 5,34 & 5,29 & 5,59 & 2,44 \\
\hline $\mathrm{TiO}_{2}$ & 0,99 & 1,48 & 0,31 & 0,62 & 1,34 & 0,38 & 0,81 & 0,26 & 0,97 & 0,30 \\
\hline $\mathbf{P}_{2} \mathbf{O}_{5}$ & 0,37 & 1,06 & 0,10 & 0,24 & 0,78 & 0,41 & 0,41 & 0,09 & 0,03 & 0,09 \\
\hline TOTAL & 99,77 & 99,30 & 99,83 & 99,57 & 99,37 & 99,75 & 99,34 & 99,78 & 99,71 & 99,71 \\
\hline $\mathrm{Cl}$ & 200 & $<\mathrm{ld}$ & 200 & 200 & 200 & $<\mathrm{ld}$ & 300 & 300 & 200 & 400 \\
\hline $\mathrm{SO}_{3}$ & 200 & 600 & 400 & 300 & 1200 & 200 & 400 & 300 & $<\mathrm{ld}$ & 400 \\
\hline $\mathbf{V}$ & $<\mathrm{ld}$ & 300 & $<\mathrm{ld}$ & 300 & 300 & $<\mathrm{ld}$ & $<\mathrm{ld}$ & $<\mathrm{ld}$ & $<\mathrm{ld}$ & $<\mathrm{ld}$ \\
\hline Ba & 700 & 1800 & $<\mathrm{ld}$ & 1300 & 1800 & 500 & 1900 & 500 & 1300 & 1000 \\
\hline $\mathrm{Sr}$ & 200 & 1900 & 200 & 600 & 1200 & 200 & 800 & 100 & 100 & $<\mathrm{ld}$ \\
\hline $\mathbf{Y}$ & 100 & 100 & 100 & 100 & 100 & 100 & 200 & 200 & 100 & 100 \\
\hline $\mathrm{Zr}$ & 700 & 1000 & 200 & 300 & 700 & 400 & 1100 & 300 & 500 & 200 \\
\hline $\mathrm{Cr}$ & $<\mathrm{ld}$ & $<\mathrm{ld}$ & $<\mathrm{ld}$ & 200 & $<\mathrm{ld}$ & $<\mathrm{ld}$ & $<\mathrm{ld}$ & $<\mathrm{ld}$ & $<\mathrm{ld}$ & $<\mathrm{ld}$ \\
\hline $\mathrm{Cu}$ & $<\mathrm{ld}$ & 100 & $<\mathrm{ld}$ & 100 & 100 & $<\mathrm{ld}$ & $<\mathrm{ld}$ & $<\mathrm{ld}$ & $<\mathrm{ld}$ & 100 \\
\hline Zn & 100 & 100 & $<\mathrm{ld}$ & 100 & 200 & $<\mathrm{ld}$ & 100 & 100 & $<\mathrm{ld}$ & 100 \\
\hline $\mathbf{R b}$ & 300 & 200 & 500 & 300 & 300 & 400 & 500 & 600 & 300 & 200 \\
\hline $\mathbf{N b}$ & 100 & $<\mathrm{ld}$ & $<\mathrm{ld}$ & $<\mathrm{ld}$ & $<\mathrm{ld}$ & 100 & 100 & $<\mathrm{ld}$ & $<\mathrm{ld}$ & $<\mathrm{ld}$ \\
\hline $\mathrm{Ce}$ & $<\mathrm{ld}$ & 900 & $<\mathrm{ld}$ & 500 & $<\mathrm{ld}$ & 400 & 1100 & $<\mathrm{ld}$ & 500 & 400 \\
\hline $\mathbf{P b}$ & $<\mathrm{ld}$ & $<\mathrm{ld}$ & $<\mathrm{ld}$ & $<\mathrm{ld}$ & $<\mathrm{ld}$ & $<\mathrm{ld}$ & 200 & $<\mathrm{ld}$ & $<\mathrm{ld}$ & $<\mathrm{ld}$ \\
\hline $\mathbf{B i}$ & $<\mathrm{ld}$ & $<\mathrm{ld}$ & $<\mathrm{ld}$ & $<\mathrm{ld}$ & $<\mathrm{ld}$ & $<\mathrm{ld}$ & $<\mathrm{ld}$ & $<\mathrm{ld}$ & $<\mathrm{ld}$ & 100 \\
\hline Th & $<\mathrm{ld}$ & $<\mathrm{ld}$ & $<\mathrm{ld}$ & $<\mathrm{ld}$ & $<\mathrm{ld}$ & 100 & $<\mathrm{ld}$ & $<\mathrm{ld}$ & $<\mathrm{ld}$ & $<\mathrm{ld}$ \\
\hline
\end{tabular}




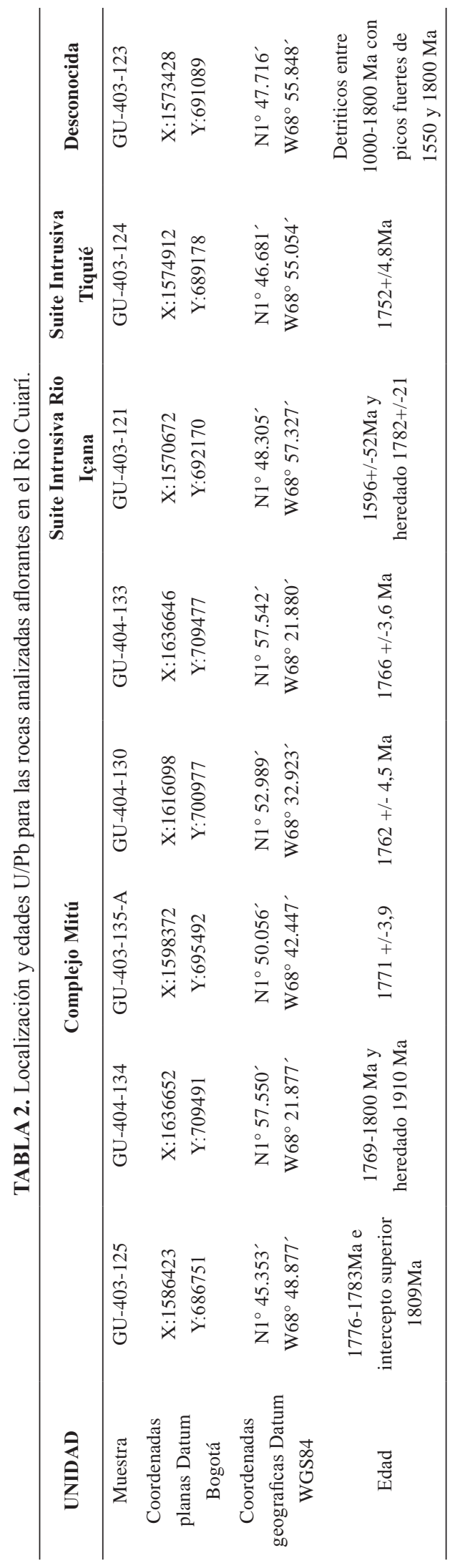




\section{Geocronología}

Se seleccionaron 8 muestras por sus características mineralógicas, texturales y su relación estratigráfica (7 rocas graníticas y 1 paragneis) de las cuales $1 \mathrm{~kg}$ por muestra fueron trituradas y tamizadas separando la fracción de 62-350 $\mu \mathrm{m}$. Se concentraron los minerales pesados de esta fracción con bateo, se retiraron los minerales ferromagnéticos (magnetita e ilmenita principalmente) con un imán de mano y después, con un separador isodinámico Frantz en la Universidad Nacional de Colombia, se separaron las fracciones con base en su susceptibilidad magnética y su masa usando corriente de 0,5, 0,9 y 1,5 A, y un ángulo lateral de $10^{\circ}$ y de cabeceo de $25^{\circ}$. La fracción separada hasta 0,5 A consiste de ilmenita, de 0,5 a 0,9 A de epidota y entre 0,9 a 1,2 A se concentraron esfena, muscovita y apatito. La fracción no magnética incluye circón, rutilo y pirita. Líquidos pesados no fueron utilizados. Sin embargo, con micro-bateo se logró remover el resto de minerales livianos. Los circones seleccionados de la última fracción por picking para el montaje en resina epoxi debían estar libres de fracturas, alteración, o cualquier otro rasgo que pueda afectar la obtención de buenos datos geocronológicos. Los montajes en resina epoxi fueron pulidos, la superficie fue fotografiada; se tomaron imágenes de los circones por backscattering SEM para un mejor posicionamiento del spot analítico.

Los análisis isotópicos fueron realizados utilizando un LA-ICP-MS con láser ESI NWR193UC acoplado a un ICP-MS cuadripolo Agilent 7700x en la Université de Rennes según el procedimiento descrito por Bühn et al. (2009). La ablación de los granos fue realizada en spots de $25 \mu \mathrm{m}$, con frecuencia de $4-5 \mathrm{~Hz}$ e intensidad de $9 \mathrm{~J} / \mathrm{cm}^{2}$. El material evaporado fue cargado por un flujo de $\mathrm{He}, \mathrm{N}_{2}$ y Ar. En todos los análisis por cada 8 mediciones en circones se utilizó un padrón GJ-1 (GEMOC ARC National Key Center, Jackson et al., 2004) para la corrección de la deriva del equipo, así como para el fraccionamiento entre los isótopos de $\mathrm{U}$ y $\mathrm{Pb}$ (Jackson et al., 2004). Las incertidumbres asociadas a las razones presentadas en el ANEXO son de $2 \sigma$, en porcentaje. Las edades fueron calculadas utilizando ISOPLOT 3.0 (Ludwig, 2003) y los diagramas $(95 \%$ de confianza) fueron confeccionados en el mismo programa.

\section{RESULTADOS}

\section{Petrografía y geoquímica}

Las observaciones de campo y características petrográficas y geoquímicas confirman para la mayoría de los gneises, granitoides y pegmatitas del área de estudio su pertenencia al Complejo Mitú que en Brasil es descrito como Complejo Cumati. Otras rocas ígneas coinciden más con las Suites Intrusivas Rio Içana y Tiquié, unidades descritas en Brasil a una distancia menor de $14 \mathrm{~km}$ del área de estudio. Un tercer grupo de cuarcitas, meta-arenitas y paragneises fueron identificados inicialmente como pertenecientes al Grupo Tunuí. En este subcapítulo nos detenemos en las características petrográficas de las rocas ígneas, mientras las observaciones de campo, petrografía y resultados e interpretaciones geoquímicas de las diferentes unidades encontradas en el área de estudio se detallan en los subcapítulos correspondientes. Su correlación geocronológica se realiza más adelante.

Las rocas ígneas en general exhiben una textura fanerítica y porfirítica, también se pueden observar texturas especiales como mirmequítica, antipertítica, pertítica y poiquilítica, sus cristales pueden alcanzar tamaños mayores a $1 \mathrm{~cm}$, son holocristalinas, en su mayoría inequigranulares y melanocráticas, cuyo tamaño de los cristales varía de medio a grueso (>1 $\mathrm{mm}$ ). Consisten principalmente de cuarzo, plagioclasas (albita-oligoclasa) y feldespatos potásicos (microclinaortoclasa). Los minerales accesorios generalmente son biotita, muscovita, apatito, esfena, epidota y circón (FIGURA 3). Excepcionalmente, en la muestra GU403-135-A se identificó hornblenda (FIGURA 3E, 3F). En todas las rocas ígneas el cuarzo se encuentra en cristales generalmente anhedrales, sin signos de meteorización, aunque se presentan cristales fracturados en los cuales parecen haber precipitado fluidos circulantes (hidro-) óxidos de hierro. Granos de cuarzo de menor tamaño forman inclusiones o intercrecimiento en cristales de plagioclasa y/o feldespato potásico, constituyendo textura poiquilítica y mirmequítica respectivamente. El feldespato potásico (únicamente encontrado como microclina) forma cristales euhedrales y subhedrales, con macla 
en enrejado, con extinción recta y en varios casos fuertemente alterados a caolín. Sus fenocristales con textura poiquilítica presentan generalmente inclusiones de cuarzo, plagioclasa y biotita; a veces se observa también desmezcla pertítica de plagioclasa e intercrecimiento mirmequítico con cuarzo. Las plagioclasas (albita-oligoclasa) suelen formar cristales anhedrales y subhedrales, con extinción según macla entre $5^{\circ}$ y $25^{\circ}$ (método de Michel-Levy), con maclado de la albita, periclina y Carlsbad. A veces la desmezcla de microclina conforma una textura antipertítica pronunciada. En muchos casos las plagioclasas están fuertemente sericitizados y epidotizados, hasta un casi total reemplazamiento por muscovita. La biotita presenta pleocroísmo marrón, en cristales subhedrales, generalmente se encuentra asociada a los halos de oxidación que presentan los opacos y suele estar alterada parcial o totalmente a clorita. Las hornblendas se distinguen por su pleocroísmo fuerte verdoso en cristales subhedrales a anhedrales (FIGURA 3E-3F).
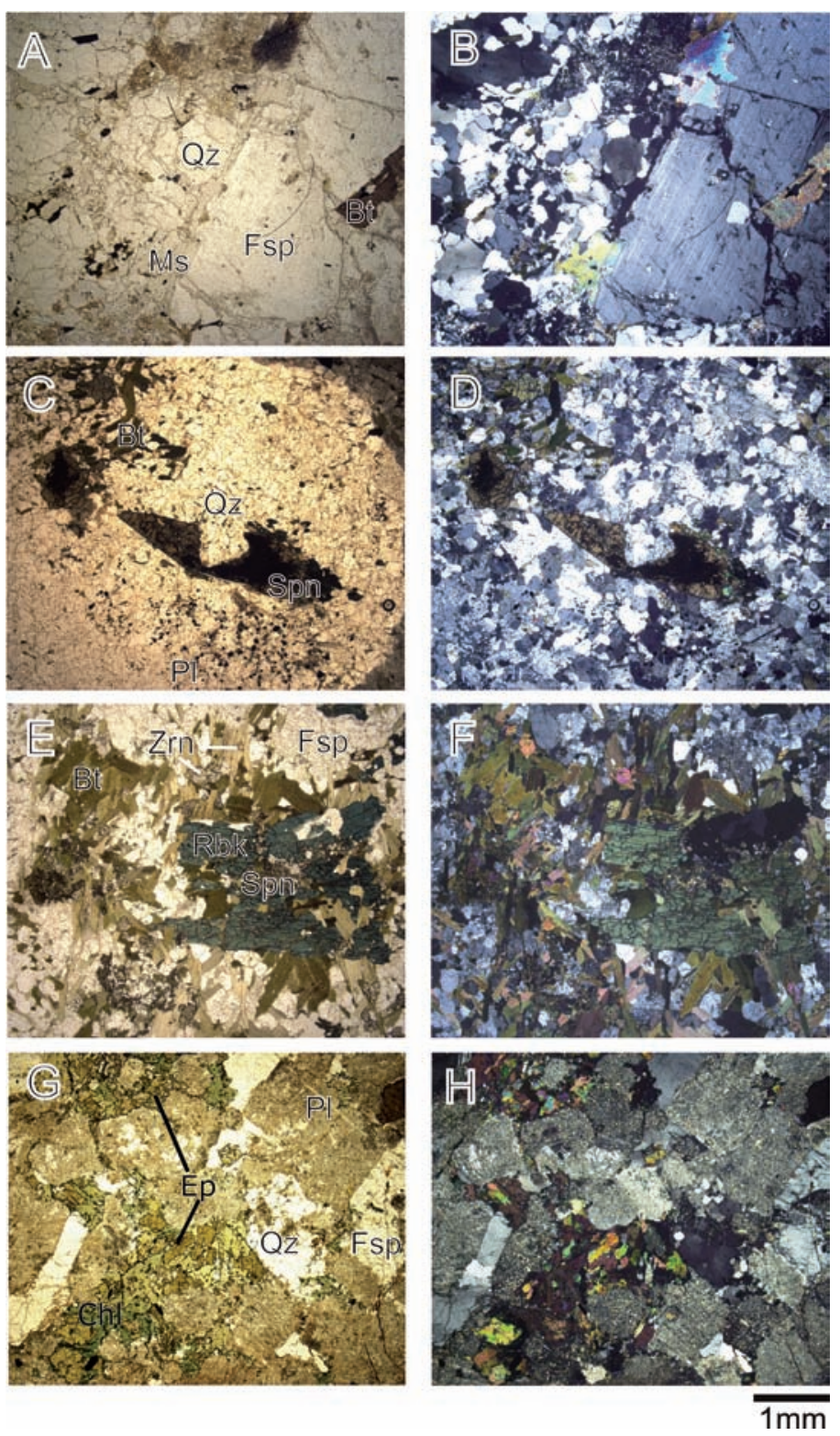

FIGURA 3. Microfotografías de rocas analizadas del Río Cuiarí (izq. PPL, der. XPL; Qz cuarzo, Pl plagioclasa, Fsp feldespato potásico, Ms muscovita, Spn esfena, Zrn circón, Hbl hornblenda, Ep epidota, Chl clorita): A-B. Granito de dos micas (Ms+Bt) con microclina y cuarzo afín a la Suite Intrusiva Rio Içana (GU-403-121). C-D. Cristal de esfena con inclusiones de opacos, en matriz de cuarzo, biotita y plagioclasa en cuarzo-monzodiorita del Complejo Mitú (GU-403-135-A). E-F. Cristales de hornblenda en la misma cuarzo-monzodiorita del Complejo Mitú (GU-403-135-A). G-H. Epidota y clorita secundarias en cuarzo-monzodiorita del Complejo Mitú (GU-404-133). 
La utilidad de los datos geoquímicos obtenidos por XRF se limita principalmente a los elementos mayores y algunos traza (TABLA 1), pero debido a los límites de detección no suficientes elementos geotectónicos tan importantes como $\mathrm{Nb}, \mathrm{Y}$, Th, La fueron detectados con suficiente precisión; si $\mathrm{Y}$ tiene en todas las mediciones un valor exacto de $100 \mathrm{ppm}$ y solamente para las rocas de la Suite Intrusiva Tiquié con 200 ppm no se puede sobreestimar estos valores. Sin embargo, dejan ver ciertas tendencias, como un enriquecimiento parcial en relación al promedio de la Corteza Superior (FIGURA
4), que se van a discriminar en los subcapítulos de las diferentes rocas y unidades. Posiblemente los elementos $\mathrm{Na}$ y $\mathrm{K}$ son subvalorados como lo sugiere la comparación del diagrama Streckeisen (FIGURA 5). En la mayoría de los elementos mayores (menos $\mathrm{Na}$ y K que muestran mayor dispersión) se confirma una correlación negativa con $\mathrm{SiO}_{2}$ (FIGURA 6), igualmente como para Ba y $\mathrm{Sr}$ (no mostrados aquí). A la par se puede observar una correlación negativa de Ti con $\mathrm{Si}, \mathrm{Rb}$ y de $\mathrm{A} / \mathrm{CNK}$, y una correlación positiva con $\mathrm{Al}, \mathrm{Mg}, \mathrm{Fe}, \mathrm{P}, \mathrm{Ba}, \mathrm{Sr}$ y Zr (FIGURA 7).

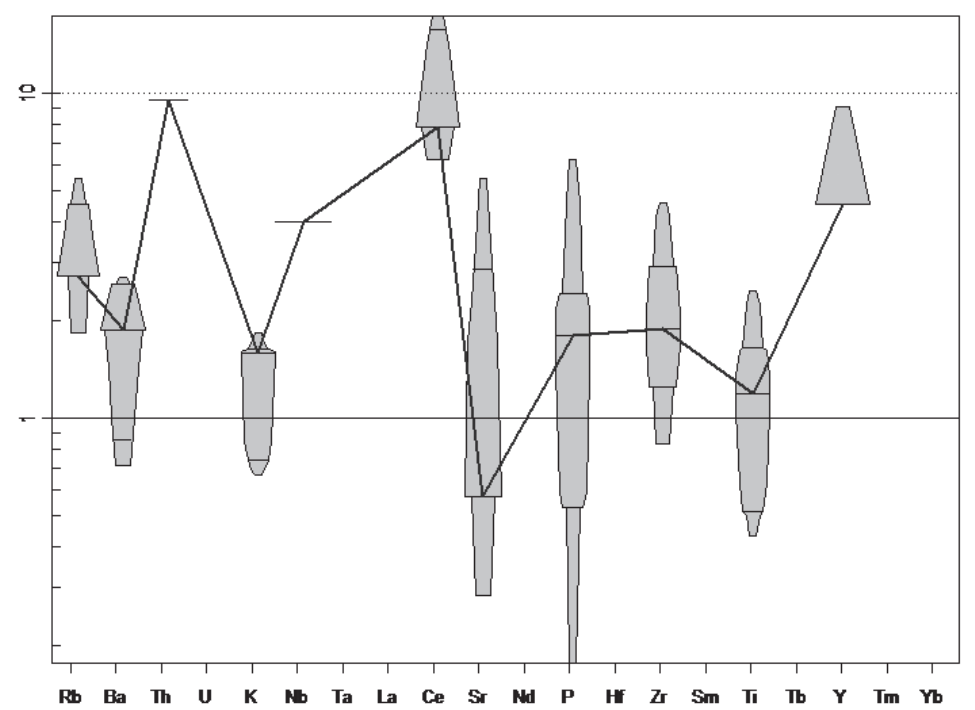

FIGURA 4. Diagrama spider (boxplot) de todas las rocas analizadas indicando un cierto enriquecimiento en relación a la Corteza Superior (Taylor y McLennan, 1985).

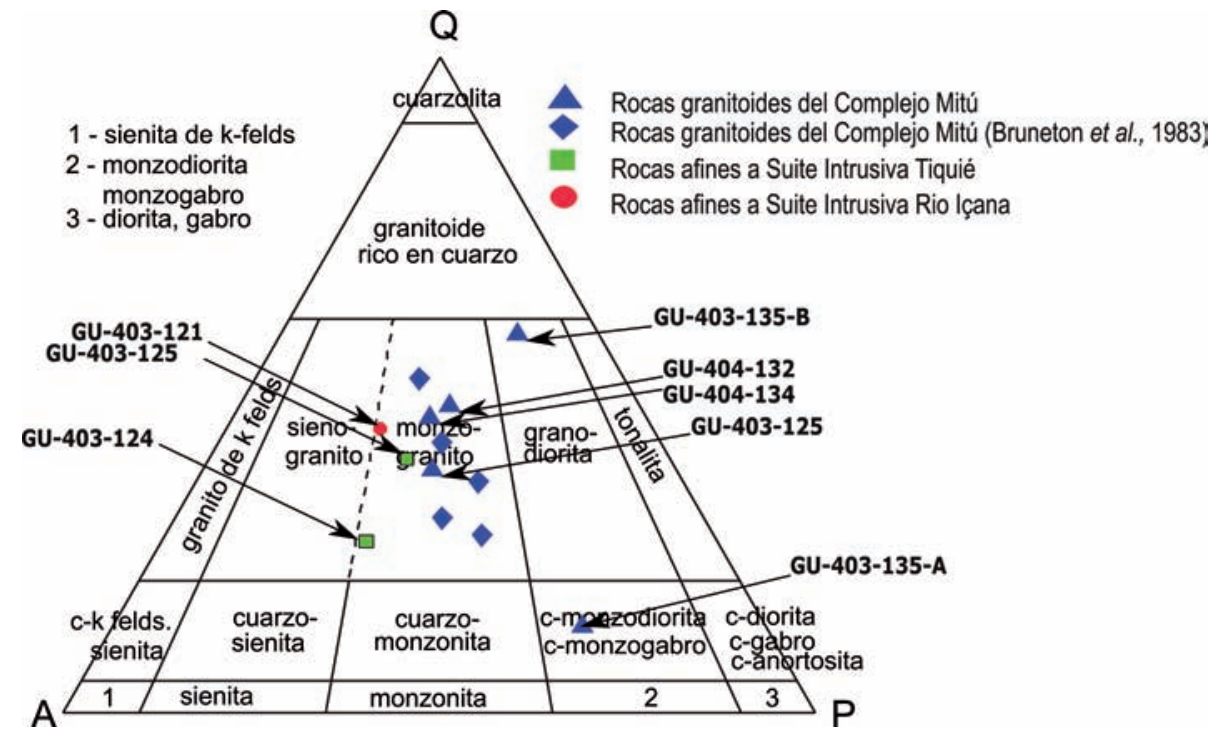

FIGURA 5. Campos composicionales (Streckeisen, 1967) de las rocas plutónicas colectadas alrededor del Río Cuiarí y de granitoides del Complejo Mitú reportados por Bruneton et al. (1983). Todas las muestras corresponden a monzogranitos, solamente dos granodioritas - pese a su alto contenido de cuarzo - y dos monzodioritas son más máficos. 

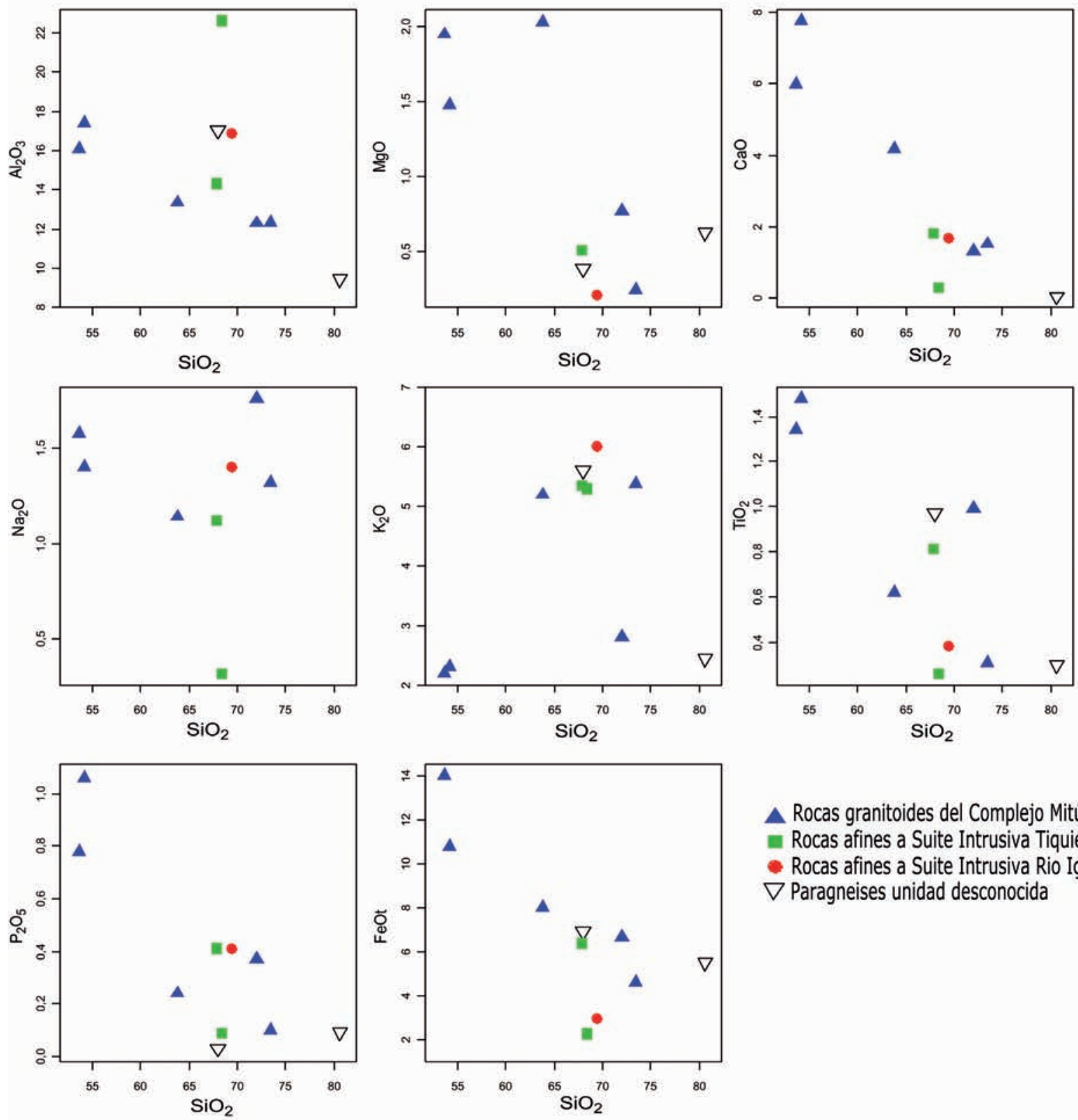

- Rocas granitoides del Complejo Mitú - Rocas afines a Suite Intrusiva Tiquié - Rocas afines a Suite Intrusiva Rio Içana $\nabla$ Paragneises unidad desconocida

FIGURA 6. Diagramas multiplot de $\mathrm{SiO}_{2}$ vs elementos mayores mostrando una correlación negativa en la mayoría de los elementos. 

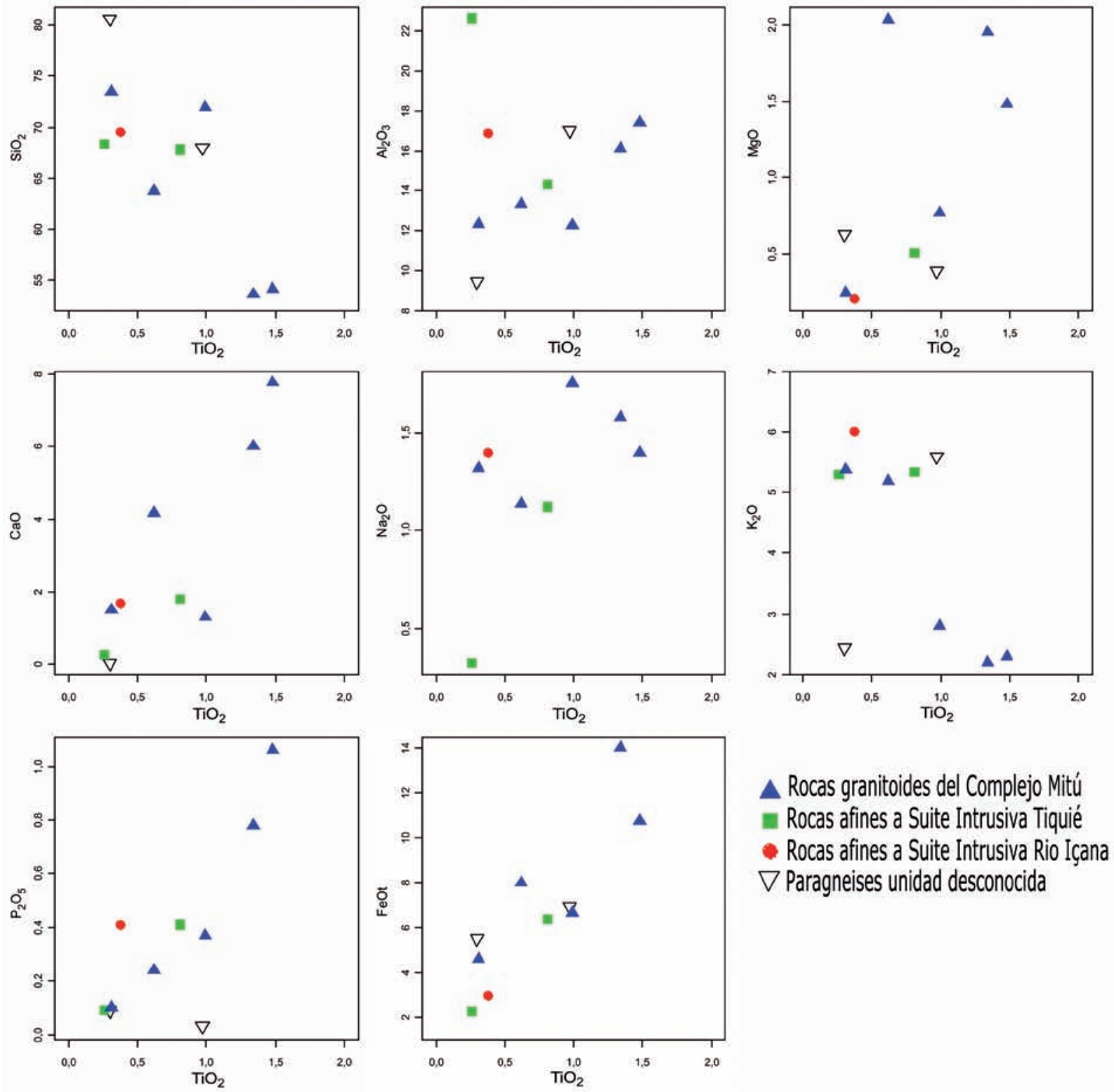

FIGURA 7. Diagramas multiplot de $\mathrm{TiO}_{2}$ vs elementos mayores mostrando una correlación positiva en la mayoría de los elementos menos Si y K.

\section{Rocas del Complejo Mitú}

\section{Gneises y migmatitas}

A lo largo del Río Cuiarí y la parte alta de Caño Naquén los afloramientos de rocas metamórficas del Complejo Mitú son muy esporádicos, tienen una expresión morfológica llana y tienden a ser inundadas por el río en épocas de invierno. Entre las comunidades indígenas de Barranquilla y Miraflores (FIGURA 2) de $80 \mathrm{~km}$ de distancia se encuentra solo uno de estos afloramientos en la estación GU-404-131 (FIGURA 2), cuyas texturas de foliación y/o bandeamiento son notorias y están definidas por las siguientes características: bandeamiento composicional de cuarzo, feldespato potásico y plagioclasa vs biotita y alineamiento de cristales. Aquí corresponde a un ortogneis compuesto de cuarzo, feldespato potásico, plagioclasa, biotita, y esfena. La textura es bandeada en dirección N40W, se encuentran acumulaciones de biotita cloritizada (FIGURA 8A-8B) y es cortada por 
diques pegmatíticos cuarzo-feldespáticos de hasta 5 $\mathrm{cm}$ de espesor. La meteorización de estas zonas con mayor contenido de minerales máficos deja formas acarcavadas, a diferencia de los granitos cercanos con meteorización esferoidal. La radioactividad de la roca metamórfica marca $0,40 \mu \mathrm{Sv} / \mathrm{h}$, de las acumulaciones de biotita $0,29 \mu \mathrm{Sv} / \mathrm{h}$ y de las pegmatitas $0,44 \mu \mathrm{Sv} / \mathrm{h}$.

\section{$\underline{\text { Granitoides }}$}

Los granitoides del Complejo Mitú analizados en el sur del Departamento de Guainía son petrográficamente en su mayoría monzogranitos, pero con variaciones más máficas hacia granodioritas y cuarzo-monzodioritas (FIGURA 5). Geoquímicamente son granitoides férricos, calcoalcalinos-cálcicos, peraluminosos a metaluminosos y con características de granitos sin-colisionales a pos-orogénicos (FIGURA 9). En las estaciones GU-404-132 y GU-404-134 sobre el camino que comunica al Río Cuiarí con Caño Naquén, aflora un monzogranito de grano grueso inequigranular (FIGURA 8C) compuesto de cuarzo $42 \%$, plagioclasa $24 \%$, feldespato potásico $27 \%$ y biotita $3 \%$, con radioactividad de $0,26 \mu \mathrm{Sv} / \mathrm{h}$. Otro monzogranito de composición similar pero por su grano fino texturalmente diferente fue observado en la estación GU-403-125 (FIGURA 2) en donde es intruído por rocas afines con la Suite Intrusiva Tiquié; allí se presenta como fino-equigranular leucocrático, compuesto de cuarzo 36\%, feldespato potásico 33\%, plagioclasa $24 \%$, biotita $3 \%$ y muscovita $2 \%$ (FIGURA $8 \mathrm{D})$ y una mayor radioactividad de $0,57 \mu \mathrm{Sv} / \mathrm{h}$. Llaman la atención diques pegmatíticos irregulares de cuarzo, feldespato potásico, biotita y muscovita.

La roca de la estación GU-404-130 (FIGURA 2) presenta grano medio equigranular, es leucocrática de composición granodiorítica con cuarzo, plagioclasa, feldespato potásico, biotita, epidota y esfena. Microscópicamente presenta una orientación de los cristales y marca una radioactividad de 0,34 $\mu \mathrm{Sv} / \mathrm{h}$. Una cuarzo-monzodiorita $\mathrm{y}$ al lado una granodiorita en cercanías a la Comunidad Indígena de Barranquilla (GU-403-135) dan pistas interesantes, aunque desafortunadamente la cobertura vegetal y de suelos no permitió trazar su correlación en campo. La cuarzo-monzodiorita con cristales de alrededor $0,3 \mathrm{~mm}$ de cuarzo $7 \%$, plagioclasa $30 \%$, feldespato potásico $16 \%$, contiene parches particularmente grandes de biotita $18 \%$ y de hornblenda $\sim 15 \%$, esfena $9 \%(>2 \mathrm{~mm})$ y circones irregularmente distribuidos (FIGURA 3C-3F); una parte de los minerales opacos que se deja atraer por un imán son magnetitas. Otra cuarzo-monzodiorita con algo más de plagioclasa que la anteriormente descrita fue observada en GU404-133 donde se presenta con alta meteorización puesto que la biotita presenta cloritización y también se encuentra epidota; algunas venas de epidota han generado deformación de micas (FIGURA 3G-3H). Geoquímicamente (TABLA 1) se encuentran en el rango normal de monzodioritas con bajo $\mathrm{Si}$; contiene más $\mathrm{Fe}, \mathrm{Al}$, Ca y $\mathrm{P}$ y menos $\mathrm{Mg}$ comparado con unas 20 monzodioritas con $\mathrm{SiO}_{2}$ alrededor de 54\% (de una base de datos de 557 monzodioritas extraída de EarthChem.org); también las concentraciones de Ba, $\mathrm{Sr}, \mathrm{Ce}$, Ti y $\mathrm{Zr}$ son relativamente altas, los tres últimos en concordancia con abundantes apatitos, circones y esfenas observadas. Posiblemente los apatitos contienen algo de Th, indicado por una radioactividad levemente elevada en el testigo de la sección delgada $(\sim 0,35 \mu \mathrm{Sv} / \mathrm{h})$, aunque ni Th ni $\mathrm{U}$ fueron detectados por XRF. En los diagramas de Frost et al. (2001) estas cuarzo-monzodioritas ocupan el campo férrico, cálcico a cálcico-alcalino y meta a peraluminoso y sus contenidos de $\mathrm{Mg}, \mathrm{Ca}$ y $\mathrm{Al}$ (factor R2 de Batchelor y Bowden, 1985) indican ambientes geotectónicos de colisión pre-placa (FIGURA 9). El significado de la gran similitud geoquímica de los contenidos de elementos analizados de estas cuarzo-monzodioritas de tendencia máfica con el promedio de la Corteza Inferior (Taylor y McLennan, 1985) es objeto de estudios en curso.

La granodiorita al lado del afloramiento de la cuarzomonzodiorita es más leucocrática, de grano más grueso $(\sim 1 \mathrm{~mm})$ y contiene cuarzo $46 \%$, plagioclasa $24 \%$, feldespato potásico $9 \%$, biotita $12 \%$, muscovita $3 \%$, abundante apatito y opacos. Sus elementos mayores la ubican de una selección de $\sim 12.900$ muestras de granodioritas extraídas de EarthChem.org en el rango de las granodioritas con relativamente mucho Si pero muy poco $\mathrm{Al}$ lo que se refleja en el alto contenido de cuarzo de casi $50 \%$. Si la comparamos con $\sim 300$ muestras de $\sim 72 \% \mathrm{SiO}_{2}$ encontramos que hay alta coincidencia con una granodiorita de $12,4 \% \mathrm{Al}_{2} \mathrm{O}_{3}$ con $46 \%$ de cuarzo del Uchi-Greenstone belt en Ontario (Thurston y Fryer, 1983); todas las demás granodioritas de esta selección global de $72 \% \mathrm{SiO}_{2}$ contienen más $\mathrm{Al}_{2} \mathrm{O}_{3}$ hasta $19 \%$. También $\mathrm{Fe}_{2} \mathrm{O}_{3} \mathrm{t} 7,42 \%$ es inusualmente alto mientras $\mathrm{MnO} 0,05 \mathrm{y} \mathrm{MgO}$ 0,77 se encuentran en el rango normal de granodioritas; $\mathrm{K}_{2} \mathrm{O} 2,81 \%$ y $\mathrm{Na}_{2} \mathrm{O}$ 1,76\% son bajo en relación con $\mathrm{CaO}$ 1,31\% para una roca con tanto $\mathrm{SiO}_{2}$, mientras los relativamente altos valores de $\mathrm{TiO}_{2}$ 0,99\% y $\mathrm{P}_{2} \mathrm{O}_{5}$ 0,37\% se reflejan en la presencia de apatitos y posiblemente ilmenita entre los opacos. 

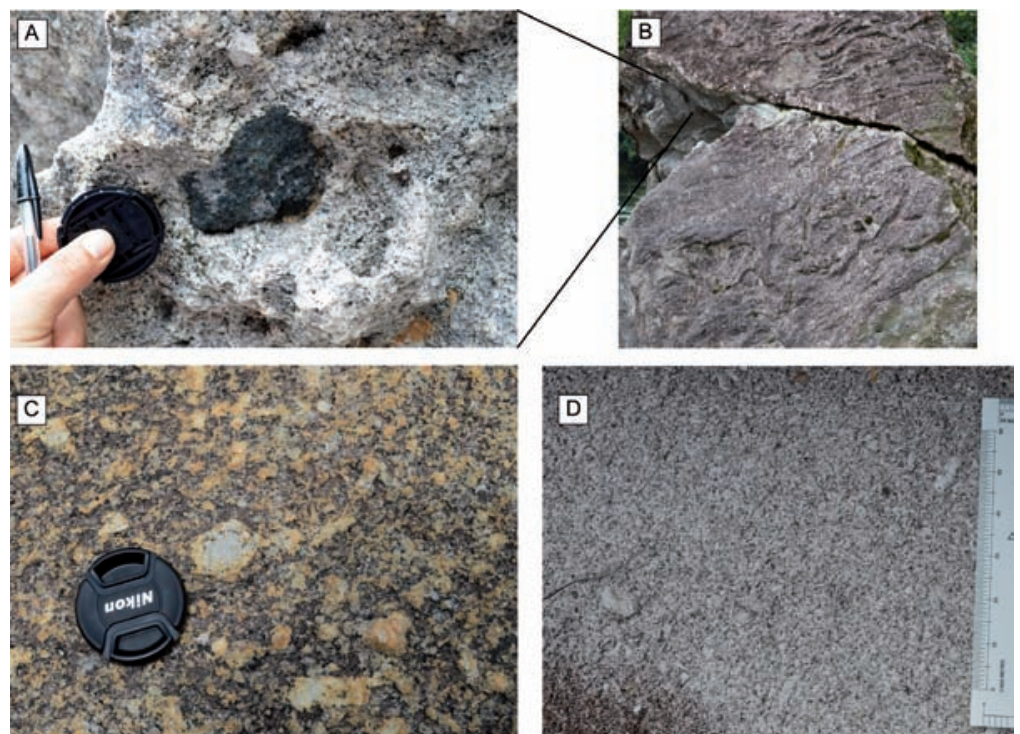

FIGURA 8. Rocas del Complejo Mitú. A-B. Textura bandeada y acumulaciones de biotita cloritizada en ortogneis (GU-404131). C. Monzogranito grueso-inequigranular (GU-404-132). D. Monzogranito finogranular (GU-403-125).
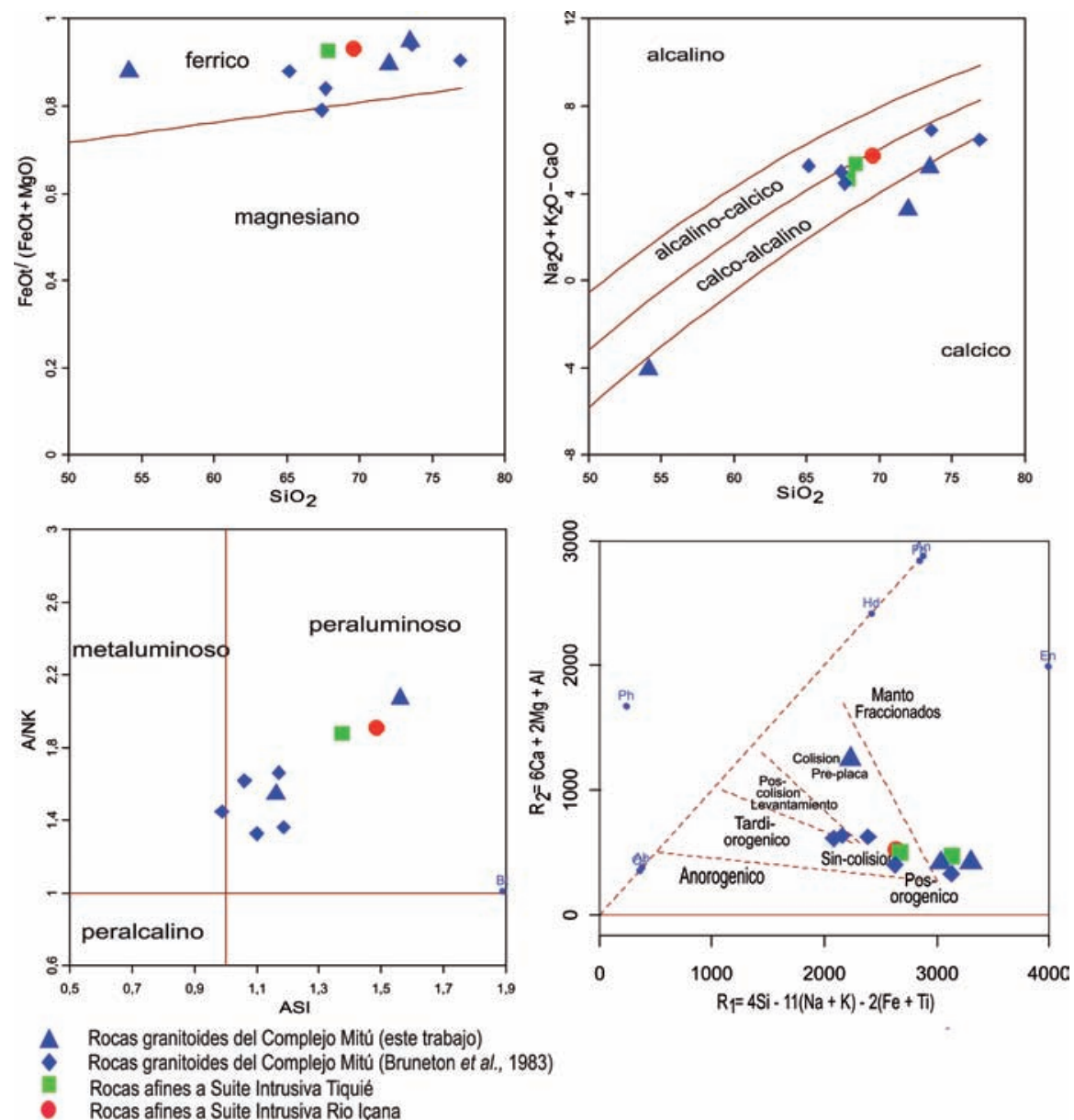

FIGURA 9. A-B-C. Diagramas de variación composicional Al, Si, Fe, Na, K, Mg (Frost et al., 2001). D. Diagrama geotectónico R1-R2 (Batchelor y Bowden, 1985) de las rocas granitoides del Complejo Mitú según Bruneton et al. (1983) y aflorantes en el Río Cuiarí estudiados en este trabajo. Nótese un carácter tendencialmente más férrico y peraluminoso de las rocas afines a las Suites intrusivas Tiquié y Rio Içana en comparación con la mayoría de las rocas del Complejo Mitú graficadas. 


\section{Manifestaciones de la Suite Intrusiva Tiquié}

En Brasil es descrita la Suite Intrusiva Tiquié (Pinheiro et al., 1976) con textura porfirítica característica, compuesta de monzogranitos biotíticos, sienogranitos y raramente granitos de feldespato alcalino y una edad de 1749 $\pm 5 \mathrm{Ma}$ (en Almeida et al., 2004). En el área de estudio es posible identificar rocas afines con esta unidad a escala cartografiable, donde se extiende desde el Raudal Garganta (GU-403-124) aguas abajo con afloramientos intermitentes a lo largo de $\sim 13 \mathrm{~km}$ en las márgenes del Río Cuiarí. Aflora como un monzogranito-sienogranito de textura porfirítica, leucocrática, compuesto principalmente de cuarzo $21 \%$, feldespato potásico $43 \%$, plagioclasas $21 \%$, biotita $8 \%$ y muscovita $2 \%$ (FIGURA 10). Geoquímicamente es calco-alcalino, peraluminoso, presenta alto contenido de hierro en comparación con magnesio y características sin-colisionales a posorogénicas (FIGURA 9). Esta roca con fenocristales ovoides de feldespato potásico sin orientación y una cantidad de muscovita menor de $2 \%$ es textural y mineralógicamente muy diferente a los granitoides del Complejo Mitú; en la estación GU-403-125 se observó como este granito porfirítico intruye a un granito de textura fina perteneciente al Complejo Mitú (FIGURA 10A, 10B, 10C), que dejó en la zona del contacto intrusivo xenolitos más claros (FIGURA 10D). La radioactividad medida de esta intrusión con $0,72 \mu \mathrm{Sv} / \mathrm{h}$ es considerable mayor que los $0,57 \mu \mathrm{Sv} / \mathrm{h}$ medidos del monzogranito del Complejo Mitú intruido. Así mismo es un cuerpo diferenciable de rocas afines a la Suite Intrusiva Río Içana (descrito más adelante). Contienen más $\mathrm{Si}, \mathrm{K}, \mathrm{Rb}, \mathrm{Rb} / \mathrm{Sr}$ y menos $\mathrm{Mg}, \mathrm{Ca}, \mathrm{Ti}, \mathrm{P} \mathrm{Fe}, \mathrm{Sr}, \mathrm{y}$ Ba que las rocas medidas del Complejo Mitú.
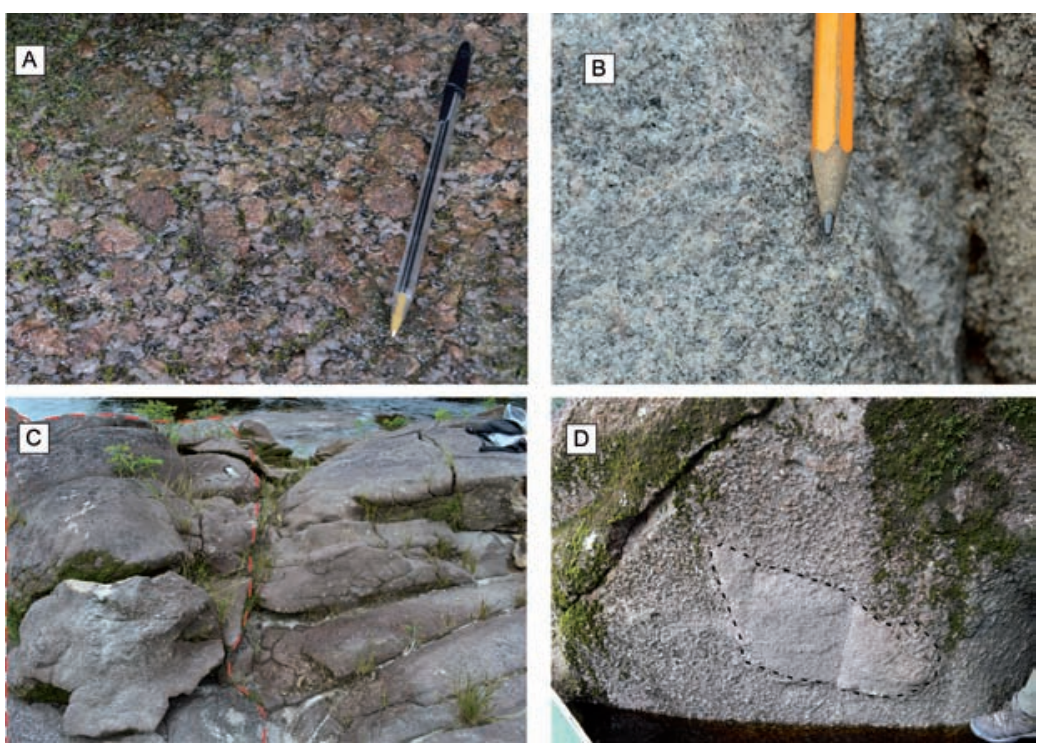

FIGURA 10. A. Manifestaciones de la Suite Intrusiva Tiquié en el Raudal Garganta, monzogranito porfirítico. B. Monzogranito equigranular del Complejo Mitú. C. Contacto intrusivo entre la Suite Intrusiva Tiquié y el Complejo Mitú (línea roja discontinua). D. Xenolito más claro y fino del Complejo Mitú incorporado en monzogranito de la Suite Intrusiva Tiquié.

\section{Manifestaciones metasedimentarias del Grupo Tunuí}

Toussaint (1993) usó el término Grupo Tunuí en Colombia para rocas de la Serranía de Naquén en equivalencia de la Formación La Pedrera introducida por Galvis et al. (1979). Esta unidad meta-arenítica fue estudiada en territorio brasileño por primera vez por Paiva (1928) en la Cachivera de Tunuí, sobre el Río Içana, en la serranía del mismo nombre, y descrita como cuarcitas sericíticas que se prolongan al norte en territorio colombiano. Amaral (1974), basándose en imágenes regionales de radar, planteó que el Grupo Tunuí es la extensión plegada y metamorfoseada de la
Formación Roraima hacia el occidente, pero los estilos tectónicos diferentes observados en campo descartaron esta hipótesis. Según Montalvao y Fernandes (1975) la Serranía de Caparro es la continuación en Brasil de la Serranía de Naquén como parte del Grupo Tunuí conformado por cuarcitas, cuarcitas de muscovitaclorita-biotita y filonitos.

Renzoni (1989a) propuso para las secuencias metasedimentarias de la Serranía de Naquén el nombre Formación Maimachi, pero poco después (Renzoni 1989b) propone "adoptar la nomenclatura propuesta 
por los geólogos brasileños, por las siguientes razones: la continuidad de las capas de la Serranía de Naquén y aquellas de la Serranía de Caparro, la corta distancia de $20 \mathrm{~km}$ que separan la Serra de Caparro de la Serra de Tunuí, y principalmente, por la definición del Grupo Tunuí perfectamente válida para describir las características composicionales y texturales de la secuencia de Naquén y sus relaciones estratigráficas". También Santos et al. (2003) atribuyen las rocas supracorticales a lo largo de la frontera Brasil Colombia (serranías de Traira-Caparro-Naquén y OnçaCaranacoa) al Grupo Tunuí. Por todo eso admitimos también en este trabajo la secuencia meta-sedimentaria que conforma las Serranías de Caranacoa y Naquén, y el Raudal de Yurupari como parte del Grupo Tunuí.

\section{Metarenitas y cuarcitas}

En el corregimiento de Campo Alegre en la estribación sur de la Serranía de Caranacoa, la Facies Tunuí del Grupo Tunuí (Almeida et al., 2004) se manifiesta en forma de bancos de metarenitas altamente meteorizadas e intercalados con capas de filitas verdes con buzamiento N32W/50SW (FIGURA 11A) y una baja radioactividad de $0.095 \mu \mathrm{Sv} / \mathrm{h}$. En el Raudal Yuruparí del Río Cuiarí afloran de esta unidad cuarcitas con turmalina en capas competentes y con estructuras relícticas de estratificación en contacto con un cuerpo intrusivo de composición granítica (FIGURAS 11B, $11 \mathrm{E}, 11 \mathrm{~F}$ y 1112). El paquete de cuarcitas con baja radioactividad de $0,12 \mu \mathrm{Sv} / \mathrm{h}$ tiene una orientación S04E/10NE.

\section{Paragneises}

Almeida et al. (2004) describieron paragneises bandeados, polideformados y migmatíticos en la Serranía de Caparro-Brasil como la Facies TaiuaçuCauera o miembro inferior del Grupo Tunuí. En la zona de Pana-Pana al lado del Raudal Yuruparí afloran paragneises, litológicamente similares a esta facies, con bandeamiento en dirección S61W/68SE, compuestos de muscovita, biotita, cuarzo y feldespato potásico (FIGURA 11C, 11G, 11H) y cortadas por zonas de textura pegmatítica con cuarzo, muscovita y feldespato potásico. Posiblemente asociados a estas vetas se pueden observar indicios de minería de oro antigua. Los paragneises parecen estratigráficamente infrayacer las metarenitas y cuarcitas del miembro superior del Grupo Tunuí aunque una densa vegetación impide ver su contacto y sus datos estructurales no son concordantes. Este miembro no ha sido reportado todavía en Colombia, así que se hacen necesarios estudios más detallados.

\section{Manifestaciones de la Suite Intrusiva Rio Içana}

La Suite Intrusiva Rio Içana (1,52-1,54 Ga) es descrita en Brasil como un granito musco- biotítico cizallado y con señales de flujo magmático que aflora al sur de la Serranía de Naquén en contacto con metasedimentitas del Grupo Tunuí (Almeida et al., 1997; Almeida y Larizzatti, 1996). También en Colombia a lo largo del Río Cuiarí y Caño Naquén parecen aflorar representantes de esta Suite Intrusiva Rio Içana (GU-403-121,-136,-140). Un monzogranito o granito de dos micas (biotita y muscovita, FIGURAS 3A, 3B, 5) en el Raudal Yuruparí (GU-403-121) exhibe signos de cataclasis y una textura porfirítica causada por fenocristales de feldespato potásico tabulares y parcialmente orientados por flujo magmático dentro de una matriz fanerítica (FIGURA 11D). Este granito más diferenciado es compuesto principalmente de cuarzo $35 \%$, feldespato potásico $30 \%$, plagioclasas $16 \%$, biotita $8 \%$ y muscovita $8 \%$ lo que se expresa también en una radioactividad mayor de 0,599 $\mu \mathrm{Sv} / \mathrm{h}$. Geoquímicamente presenta alto contenido en hierro relativo a magnesio, es calco-alcalino, peraluminoso y con características sin-colisionales (FIGURA 9).

En el mismo Raudal Yuruparí se puede observar su contacto intrusivo con las cuarcitas del miembro superior del Grupo Tunuí donde generó turmalinas e incorporó xenolitos de cuarcita dentro del granito (FIGURA 12). Remanentes de actividad minera aurífera a lo largo del contacto hacen suponer una removilización y mayor concentración de oro por fluidos asociados al intrusivo.

\section{Geocronología U/Pb en circones}

Los datos analíticos $\mathrm{U}-\mathrm{Pb}$ medidos en circones mediante LA-ICP-MS permiten distinguir cuatro grupos de edades para las rocas identificadas en el área de estudio: a) un grupo relacionado con el metamorfismo de ortogneises y la cristalización de granitoides del Complejo Mitú; b) otro más joven relacionado con la cristalización de un cuerpo ígneo correlacionable con la Suite Intrusiva de Tiquié en Brasil, c) un tercer grupo al parecer relacionado con la cristalización de un cuerpo ígneo correlacionable con la Suite Intrusiva de Içana y con circones heredados de rocas del Complejo Mitú, y d) una mezcla de edades derivadas de circones detríticos encontrados en un paragneis sin relación geocronológica con el Grupo Tunuí. 

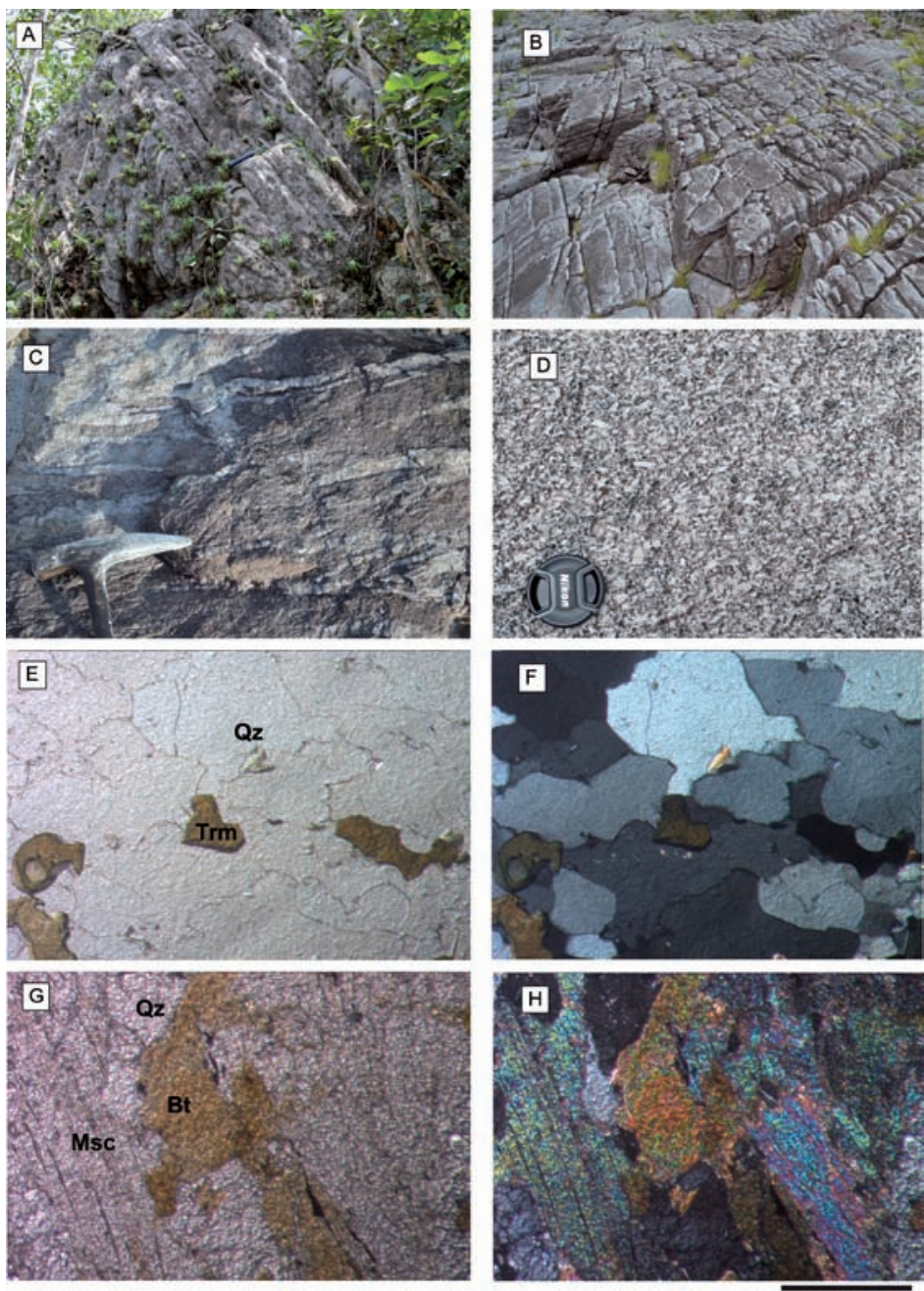

FIGURA 11. A. Metarenitas en la estribación sur de la Serranía de Caranacoa. B. Cuarcitas con estructuras relicto aflorantes en el Raudal Yuruparí, Grupo Tunuí. C. Paragneis de la Facies Taiuaçu-Cauera del Grupo Tunuí. D. Granito de la Suite Intrusiva Río Içana con textura porfirítica aflorante en el Raudal de Yuruparí. E-F. Microfotografía de la cuarcita con turmalina del Grupo Tunuí. G-H. microfotografía del paragneis del Grupo Tunuí GU-403-123. Izq. PPL, der. XPL, escala igual para las 4 fotografías. Qz: cuarzo, Bt: biotita, Ms: muscovita, Tur: turamalina.

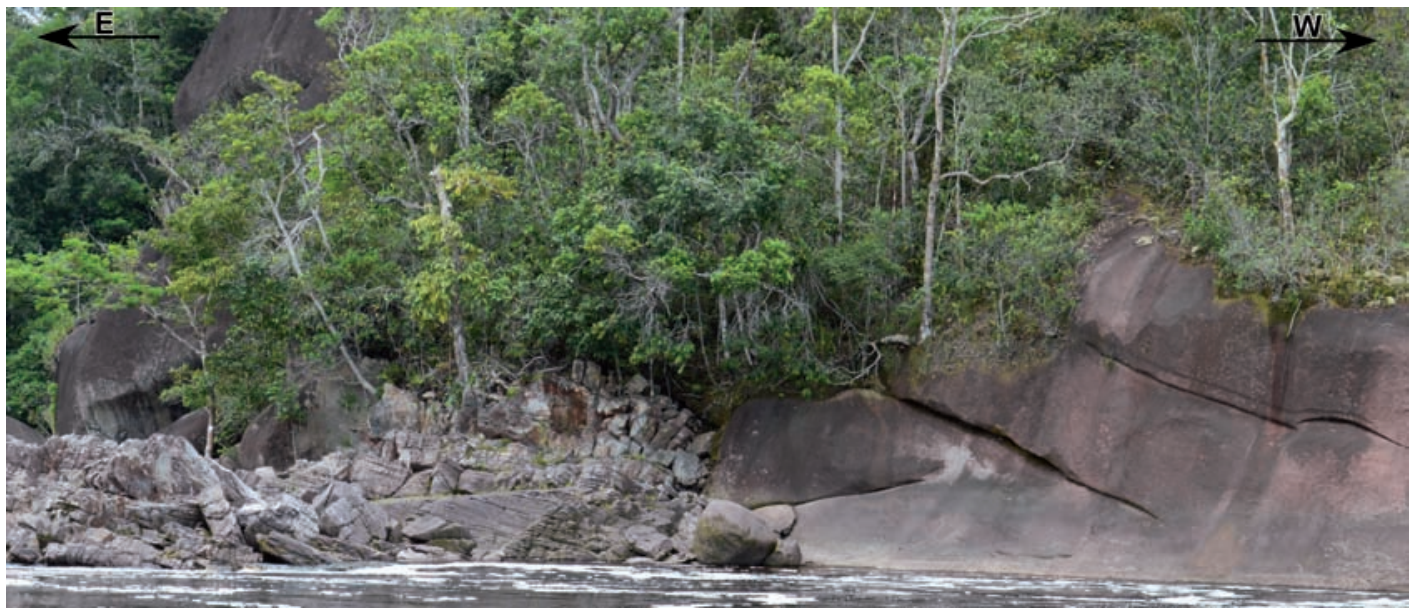

FIGURA 12. Contacto intrusivo entre el cuerpo granítico (derecha) y las cuarcitas del Grupo Tunuí (izquierda). 


\section{Edades medidas de rocas del Complejo Mitú}

Los circones extraídos de una granodiorita del Complejo Mitú (GU-404-130) de forma subhedral a euhedral, levemente redondeados, con un diámetro entre 200-300 $\mu \mathrm{m}$ permitieron obtener en 17 granos datos isotópicos de las cuales se calculó una edad concordante de $1762 \pm 4,5 \mathrm{Ma}$ (FIGURA 13A) interpretadas como edad de cristalización. De 24 y 23 granos de circones euhedrales con diámetro entre 100-200 $\mu \mathrm{m}$ de las cuarzo-monzodioritas GU-404133 y GU-403-135-A se calcularon edades concordantes de cristalización de 1766 $\pm 3,6$ Ma y 1771 $\pm 3,9$ Ma (FIGURA 13B, 13C). Circones euhedrales, prismáticos, con un diámetro entre 50-100 $\mu \mathrm{m}$ del monzogranito de la estación GU-403-125 dieron una edad discordante con intercepto superior en $1809 \pm 29 \mathrm{Ma}, 2$ granos cercanos a la concordia indican edades de 1775 y $1783 \mathrm{Ma}$ (FIGURA 13D), que se encuentran dentro del rango de error y pueden corresponder a la cristalización.

Circones euhedrales a subhedrales, con diámetro entre 50-100 $\mu \mathrm{m}$ de un monzogranito (GU-404-134) presentan demasiado plomo común $\left({ }^{204} \mathrm{~Pb}\right)$ para una datación confiable y la mayoría de granos dan edades discordantes, pero 5 análisis cercanos a la concordia indican edades entre 1769-1800 que se encuentran dentro del rango de cristalización del Complejo Mitú generalmente aceptado, y una edad de 1910 Ma corresponde probablemente a una edad heredada (FIGURA 13E).
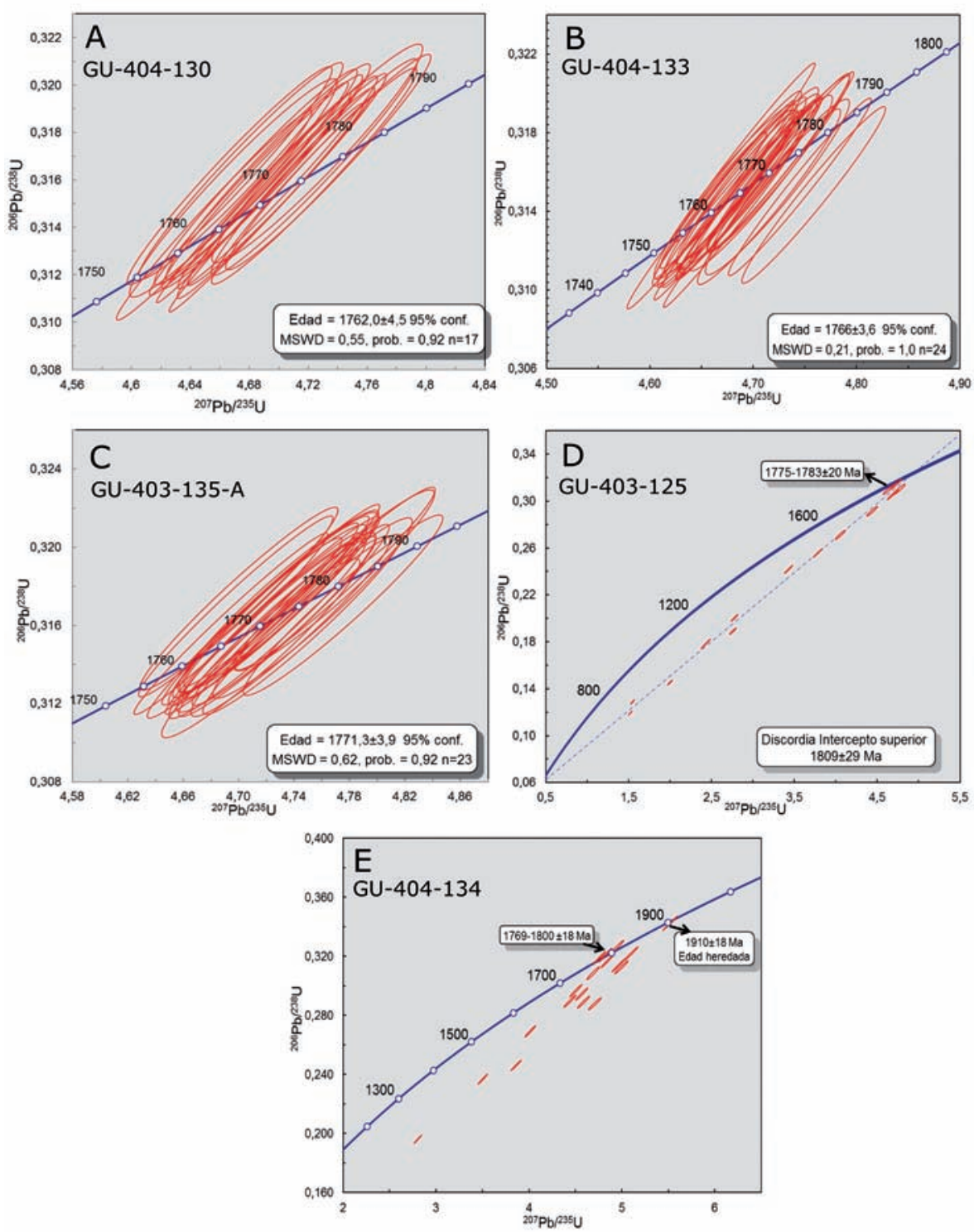

FIGURA 13. Diagramas concordia para los circones analizadas por LA-ICP-MS del Complejo Mitú en el Río Cuiarí. A. Granitoide granodioritico de la estación GU-404-130. B-C. Granitoides cuarzo-monzodioríticos GU-404-133 y GU-403-135-A. D-E. Monzogranitos GU-403-125 y GU-404-134. 


\section{Edades medidas de otras rocas intrusivas}

Circones prismáticos euhedrales a subhedrales, con diámetros 100-200 $\mu \mathrm{m}$ de un monzogranito (GU-403124) afín a la Suite Intrusiva Tiquié dieron edades discordantes con intercepto superior de $1767 \pm 13 \mathrm{Ma}$. Sin embargo, 6 edades concordantes de $1752 \pm 4,8 \mathrm{Ma}$ (FIGURA 14A) pueden ser interpretadas como edad de cristalización.

Al otro lado, el granito de dos micas (GU-403-121), posiblemente perteneciente a la Suite Intrusiva Rio Içana, contiene circones prismáticos euhedrales a subhedrales, con algo de redondeamiento que arrojan un grupo de edades discordantes de 1550-1590 Ма con intercepto superior en 1596 Ma que puede ser interpretado como la edad máxima de cristalización mientras 4 edades concordantes de 1782 \pm 21 Ma
(FIGURA 14B) se deben probablemente a circones heredados del protolito del Complejo Mitú.

\section{Edades medidas del Paragneis - Unidad desconocida}

Los circones extraídos de un paragneis con características similares a la Facies Taiuaçu-Cauera del Grupo Tunuí en Brasil (Almeida et al., 2004) son anhedrales a euhedrales, con habito prismático a subredondeado y diámetros variables entre 620-200 $\mu \mathrm{m}$. 46 circones de la muestra GU-403-123 arrojaron varios grupos de edades concordantes entre 1000-1800 Ma (FIGURA 14C, 14D) con picos fuertes a 1000, 1300, 1550 y $1800 \mathrm{Ma}$, edades que no son correlacionables con el Grupo Tunuí y representarían las varias rocas fuente acumuladas en los sedimentos pre-metamórficos y en especial 1550 y 1800 Ma que son concordantes con las edades obtenidas del Complejo Mitú y la Suite Intrusiva Rio Içana.
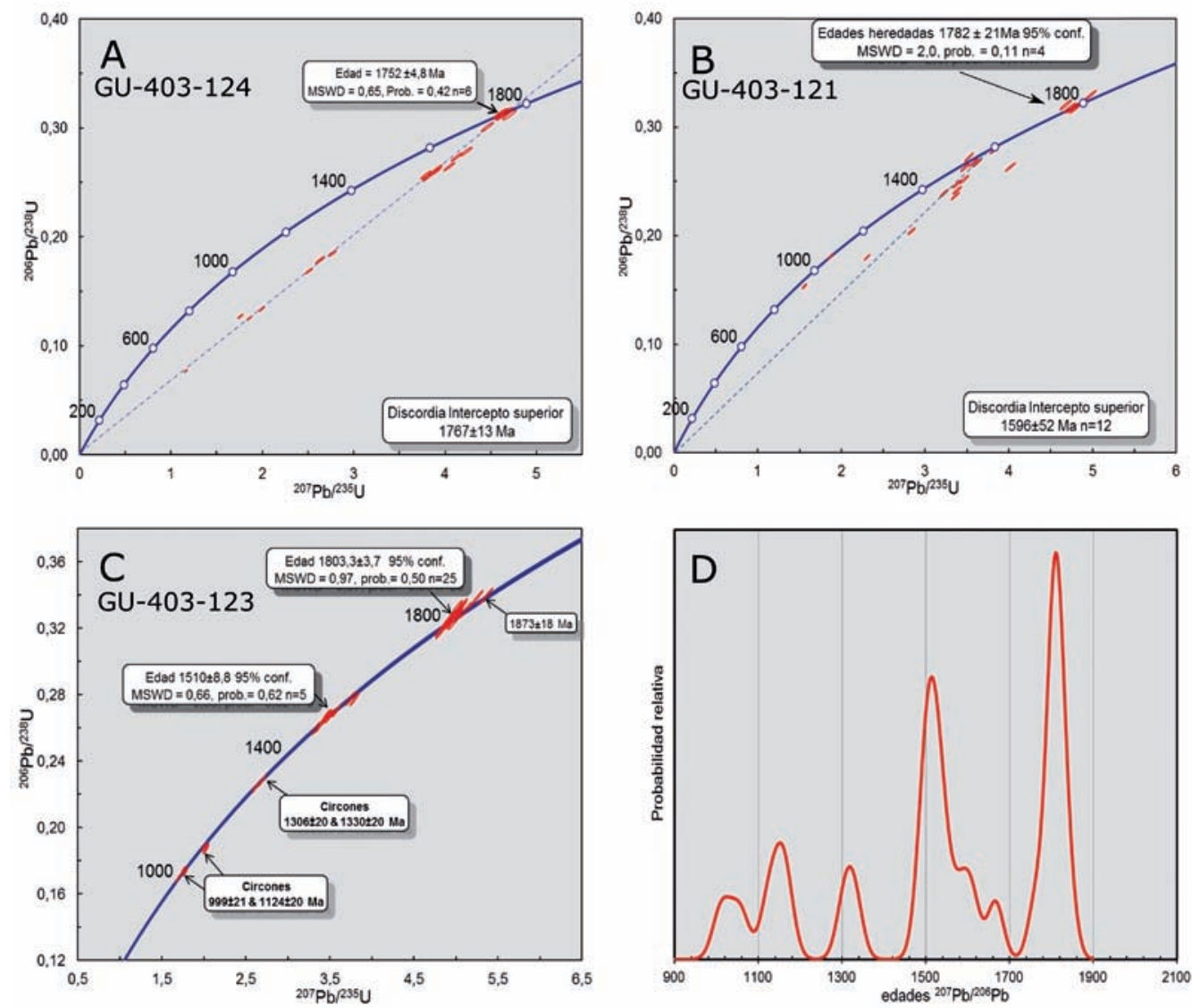

FIGURA 14. Diagramas concordia de circones analizados por LA-ICP-MS de las muestras intrusivas y del paragneis aflorantes en el Río Cuiarí. A. monzogranito porfirítico de la Suite Intrusiva Tiquie. B. Granito de dos micas Suite Intrusiva Río Içana Raudal Yurupari. C. Paragneis. D. Histograma de edades ${ }^{207 / 206} \mathrm{~Pb}$ del paragneis. 


\section{DISCUSIÓN}

Generalmente se acepta que la Provincia Geocronológica Río Negro - Juruena o la Provincia Río Negro (Santos et al., 2000; Tassinari y Macambira, 1999; Teixeira et al., 1989), a la cual pertenece el Complejo (Migmatítico de) Mitú, se haya formado principalmente por granitoides provenientes de magmas juveniles desde 1,8 hasta 1,4 Ga (Tassinari y Macambira, 1999). Sus relaciones iniciales ${ }^{87} \mathrm{Sr} /{ }^{86} \mathrm{Sr}$ entre 0,702 y 0,706 , valores $\mu 1$ alrededor de 8,0, y mayoritariamente valores positivos de $\varepsilon N d$ relativo a CHUR ( $+4 \mathrm{a}-2)$, calculados para 1,8 $\mathrm{Ga}$, sugieren un origen juvenil derivado del manto para la mayor parte de estas rocas del basamento (Tassinari et al., 1996). Sin embargo, el estudio de granitos del Bajo Vaupés de la misma provincia y la ocurrencia frecuente de rocas néisicas llevaron a Dall’Agnol (1992) a plantear la hipótesis que los granitoides del Bajo Vaupés se hayan formados a partir de rocas de corteza continental, o si se derivaron de una fuente mantélica, fueron afectados fuertemente por contaminación cortical. Esta interpretación coincide con nuestras observaciones de los granitoides del Complejo Mitú estudiados en el sur del Departamento de Guainía que geoquímicamente corresponden a granitos calcoalcalinos y per a metaluminosos, con circones heredados más antiguos (1900 Ma) y características sin-colisiónales a pos-orogénicos; lo que indica o un retrabajamiento de rocas preexistentes o contaminación cortical del magma. Igualmente, Cordani et al. (2016) concluyen de las relaciones isotópicas $\mathrm{Sr}$ y $\mathrm{Sm} / \mathrm{Nd}$ una afinidad cortical de los granitoides de esta zona, mientras Mendoza (2012) asumió que el complejo es totalmente alóctono conformado inicialmente por rocas pertenecientes al Complejo Granítico Supamo (>1,8 Ga) que fueron afectadas por la Orogenia Transamazónica y los eventos Parguazensis y Nickeriano.

En el área de estudio al sur del Departamento de Guainía en rocas aparentemente pertenecientes al Complejo Mitú se observaron ortogneises muy escasamente. Mucho más abundante son granitoides de diferentes afinidades $(>70 \%$ en extensión), principalmente monzogranitos, como fueron descritos también por otros autores (Almeida et al., 2007; Galvis et al., 1979). Por ejemplo, Rodríguez et al. (2011) asumen que la Unidad Monzogranito de Mitú PRgm separada por ellos en la Plancha 443 se extienda más hacia el occidente. Los nuevos resultados petrológicos, geoquímicos y geocronológicos comprueban procesos magmáticos y metamórficos ocurridos hace 17601800 Ma que llevaron a la formación del "Complejo Mitú", como expresión de un basamento Estateriano en consolidación a finales del Paleoproterozoico. El Cinturón Atabapo propuesto por Cordani et al. (2016) como resultado del apilamiento de arcos magmáticos en la región Atabapo-Negro-Casiquiare contra el área cratónica del proto-continente Ventuari-Tapajós hace 1800 - 1740 Ma apunta en la misma dirección. Eventos intrusivos graníticos posteriores y más diferenciados hacia 1750 y entre 1550 y $1600 \mathrm{Ma}$, se reflejan en rocas afines a la Suite Intrusiva Tiquié y Suite Intrusiva Rio Içana, respectivamente, y eran resultado de la fusión parcial de rocas del basamento Estateriano (con circones heredados del Complejo Mitú). La Suite Intrusiva Rio Içana puede ser explicada por un segundo pulso orogénico y la formación de un Cinturón Vaupés como ha sido propuesto por Cordani et al. (2016), asumiendo el apilamiento de los arcos magmáticos Mitú-Iauretê y Caquetá contra el área ya cratonizada del primer pulso, hace unos 1580 - 1500 Ma. Sin embargo, la presencia de un Cinturón Vaupés más joven hacia el suroccidente postulado por Cordani et al. (2016) aún es muy debatible, puesto que en la región donde se plantea este dominio también se encuentran rocas meta-sedimentarias correlacionables con el Grupo Tunuí (e.g. la Serranía de Taraira) la cual descansa sobre un basamento más antiguo $\sim 1750$ Ma y no como fue postulado sobre un basamento de $\sim 1500 \mathrm{Ma}$.

Las rocas meta-sedimentarias aflorantes en las Serranías de Naquén y Caranacoa pertenecen al Grupo Tunuí con una edad máxima definida por la edad del basamento de $1750 \mathrm{Ma}$ (Complejo Mitú) y una edad mínima dada por metamorfismo de contacto y metasomatismo con la intrusión de cuerpos graníticos hacia 1550-1600 Ma. Las metarenitas fueron transformadas alrededor del Raudal Yuruparí en cuarcitas que aún preservan estructura relectica y son impregnadas por turmalinas, lo que indica metamorfismo de bajo grado asociado a rocas en semejanza con la Suite Intrusiva Rio Içana. Aunque los paragneises encontrados en el Raudal Yurupari parecieran estratigráficamente corresponder al miembro inferior del Grupo Tunuí, el cual en Brasil se denomina Facies Taiuaçu-Cauera, los datos geocronológicos con picos fuertes a 1000, 1300, 1550 y 1800 Ma indican que se trata de otra unidad mucho más joven ( $<1000 \mathrm{Ma})$ en concordancia con datos similares obtenidos en paragneises de Vaupés y Guainía por Cordani et al. (2016). Su significado geológico aún no ha sido establecido, pero sus relaciones cronológicas y máxima edad de depositación permiten asociar estos paragneises al evento Grenvilliano durante el ensamblaje de Rodinia que se manifiesta en los cinturones de Sunsas y Putumayo (Ibañez et al., 2015). 
La identificación y cartografía de unidades litoestratigráficas y litodémicas en la Amazonia Brasilera es más avanzada que en Colombia, pero forma parte de un proceso continuo como lo demuestran estudios recientes (Bonilla et al., 2016; Cordani et al., 2016; Ibañez, 2011; López et al., 2007; Rodríguez et al., 2011). La mayor integración de estudios en territorio brasilero para la interpretación de unidades en territorio colombiano limítrofe evitaría incurrir en sinonimia y aportaría a un mejor entendimiento regional del basamento metamórfico-granítico incluyendo la separación de granitoides de diferentes afinidades. Por ejemplo, en el Complejo Cumati en Brasil la identificación de características litológicas, geoquímicas y geocronológicas permitió separar hasta el momento la Facies Querari y la Facies Tonu (Almeida et al., 2004; 2007).

\section{CONCLUSIONES}

Para el área de estudio en el sur del Departamento de Guainía en cercanías a Brasil las relaciones litoestratigráficas, la integración de estudios anteriores y nuevos datos petrográficos, geoquímicos, de radioactividad e isotópicos, permiten identificar mejor diferentes unidades y descifrar una historia geológica más detallada de la siguiente manera:

- El Complejo Mitú en el área de estudio como la parte más vieja reconocible ( 1760-1800 Ma) es compuesto principalmente de granitoides tipo S, monzograníticos y en menor proporción cuarzomonzoniticos a granodioriticos, calco-alcalinos, metaluminosos, cuyas nuevas edades concordantes de cristalización de 1762, 1766 y 1771 Ma, una edad discordante con intercepto superior en $1809 \pm 29$ Ma, y 2 edades cercanos a la concordia de 1775 y 1783 Ma se encuentran en el rango de edades reportadas anteriormente. En menor medida afloran ortogneises cuarzo-feldespáticos; la radioactividad medida de 0,34-0,44 $\mu \mathrm{Sv} / \mathrm{h}$ indica poca diferenciación magmática en las rocas ígneas y metamórficas en concordancia con los otros datos geoquímicos. Otro granitoide alcalino (rico en hornblenda) con una radioactividad de $0,57 \mu \mathrm{Sv} / \mathrm{h}$ deja asumir un abanico aún mayor de procesos magmáticos dentro de este complejo.

- Rocas correlacionables con la Suite Intrusiva Tiquié intruída hace $\sim 1750$ Ma representan un magmatismo granítico de textura porfirítica con fenocristales ovoides de feldespato potásico cuya mayor diferenciación magmática se refleja también en una radioactividad $>0,7 \mu \mathrm{Sv} / \mathrm{h}$.

- El Grupo Tunuí representa la depositación de secuencias sedimentarias, principalmente areniscas con baja radioactividad de 0,12 $\mathrm{SSv} / \mathrm{h}$, hace $1750-1600$ Ma que fueron afectadas posteriormente por metamorfismo de contacto y regional.

- Rocas correlacionables con la Suite Intrusiva Río Içana ( 1550-1600 Ma) con una radioactividad $\sim 0,6 \mu \mathrm{Sv} / \mathrm{h}$ representan un magmatismo evolucionado por fusión parcial de protolitos cratónicos (probablemente del hoy Complejo Mitú) que superimpuso localmente metamorfismo de contacto y metasomatismo a las rocas del Grupo Tunuí.

- Unidades metamórficas más jóvenes como el paragneis reportado en este trabajo y otros por Cordani et al., (2016), con edades en circones detríticos >1000 Ma, posiblemente están asociado con la formación del supercontinente Rodinia y la orogénesis Grenvilliana, y merecen mayor estudio para entender su importancia geotectónica y paleogeográfica.

- Rocas sedimentarias, magmáticas y metamórficas posteriores a la orogénesis Grenvilliana y antes del Cuaternario no se podían evidenciar en este trabajo, pero estudios futuros darán más claridad sobre estos puntos y varias otras preguntas no resueltas hasta el momento.

\section{AGRADECIMIENTOS}

Agradecemos a las comunidades indígenas del sur del Departamento de Guainía por permitirnos el acceso y el reconocimiento del área de estudio, especialmente al Sr. Carlos Medina por guiarnos dentro del área. Gracias al Convenio 031 de 2013 entre la Gobernación de Vaupés y la Universidad Nacional de Colombia con recursos del Sistema General de Regalías fue posible tanto la financiación de una gran parte de las comisiones de campo como de los análisis. Dr. Ricardo Arenas y un revisor anónimo contribuyeron en mejorar este trabajo notablemente. El primer autor agradece a Colciencias el otorgamiento de una beca en el marco de sus estudios de Doctorado en Geociencias. 


\section{REFERENCIAS}

Almeida, F.F.M. de, and Hasui, Y. (1984). O PréCambriano do Brasil. São Paulo: Blücher.

Almeida, F.F.M. de, Hasui, Y., Brito-Neves, B.B. de, and Fuck, R. (1981). Brazilian structural provinces: An introduction. Earth-Science Reviews, 17(1-2), 1-29. doi: 10.1016/0012-8252(81)90003-9.

Almeida, M.E., and Larizzatti, J.H. (1996). Geologia e petrografia da Suíte Intrusiva Içana no alto rio Uaupés, Estado do Amazonas, Brasil. SBG, Congresso Brasileiro de Geologia, 39. Balneário de Camboriú.

Almeida, M.E., Macambira, M.J.B., and Scheller, T. (1997). Içana Intrusive Suite: age ${ }^{207} \mathrm{~Pb} / 206 \mathrm{~Pb}$ (zircon evaporation) of muscovite bearing granite, Amazonas State, Brazil. South American Symposium on Isotope Geology, 1. Campos do Jordao.

Almeida, M.E., Luzardo, R., Pinheiro, S.S., and Oliveira, M.A. (2004). Folha NA.19-Pico da Neblina. In: C. Schobbenhaus, J.H. Gonçalves, J.O.S. Santos, M.B. Abram, R. Leão Neto, G.M.M. Matos, R.M. Vidotti, M.A.B. Ramos, J.D.A. de Jesus (Eds.). Carta Geológica do Brasil ao Milionésimo, Sistemas de Informações Geográficas-SIG. Programa Geologia do Brasil, CPRM, Brasília. CD-ROM.

Almeida, M.E., Macambira, M.J.B., Reis, N.J., Luzardo, R., and Pinheiro, S.S. (2007). Geologia, geoquímica multielementar e isotópica $(\mathrm{Sm}-\mathrm{Nd})$ das rochas do embasamento do extremo oeste da Província Rio Negro, NW do Amazonas, Brasil. $X$ Simpósio de Geologia Da Amazônia. Porto Velho, Brasil.

Amaral, G. (1974). Geologia pre-cambriana da região amazônica. PhD. Thesis, Universidade de São Paulo, Brasil.

Barrios, F., Rivas, D., Cordani, U.G., y Kawashita, K. (1985). Geocronología del Territorio Federal Amazonas. I Simposium Amazónico. Puerto Ayacucho, Venezuela.

Batchelor, R.A. and Bowden, P. (1985). Petrogenetic interpretation of granitoid rocks series using multicationic parameters. Chemical
Geology, 48(1-4), 43-55. doi: 10.1016/00092541(85)90034-8.

Bettencourt, J.S., Leite Jr., W.B., Ruiz, A.S., Matos, R., Payolla, B.L., and Tosdal, R.M. (2010). The Rondonian-San Ignacio Province in the SW Amazonian Craton: An overview. Journal of South American Earth Sciences, 29(1), 28-46. doi: 10.1016/j.jsames.2009.08.006.

Bettencourt, J.S., Tosdal, R.M., Leite Jr., W.B., and Payolla, B.L. (1999). Mesoproterozoic rapakivi granites of the Rondônia Tin Province, southwestern border of the Amazonian craton, Brazil-I. Reconnaissance U-Pb geochronology and regional implications. Precambrian Research, 95(1-2), 41-67. doi: 10.1016/S03019268(98)00126-0.

Bonilla, A., Frantz, J.C., Charão-Marques, J., Cramer, T., Franco, J.A., y Amaya, Z. (2016). Magmatismo rapakivi en la cuenca media del río Inírida, departamento de Guainía, Colombia. Boletín de Geología, 38(1), 17-32. doi: 10.18273/revbol. v38n1-2016001.

Brito-Neves, B.B. de (2011). The Paleoproterozoic in the South-American continent: Diversity in the geologic time. Journal South American Earth Sciences, 32(4), 270-286. doi: 10.1016/j. jsames.2011.02.004.

Bruneton, P., Pallard, B., Duselier, D., Varney, E., Bogotá, J., Rodríguez, C., y Martin, E. (1983). Contribución a la geología del oriente de las Comisarías del Vichada y del Guainía (Colombia). Geología Norandina, 6, 3-12.

Bühn, B., Pimentel, M.M., Matteini, M., and Dantas, E.L. (2009). High spatial resolution analysis of $\mathrm{Pb}$ and $\mathrm{U}$ isotopes for geochronology by laser ablation multi-collector inductively coupled plasma mass spectrometry (LA-MC-ICP-MS). Anais da Academia Brasileira de Ciências, 81(1), 99-114. doi: 10.1590/S0001-37652009000100011.

Condie, K.C. (2005). Earth as an evolving planetary system. Amsterdam: Elsevier/Academic Press.

Cordani, U.G., Sato, K., Sproessner, W., and Fernandes, F.S. (2016). U-Pb zircon ages of rocks from the Amazonas Territory of Colombia and their bearing on the tectonic history of the NW sector 
of the Amazonian Craton. Brazilian Journal of Geology, 46(1), 5-35. doi: 10.1590/23174889201620150012.

Costa, J.B., and Hasui, Y. (1997). Evolução Geológica da Amazônia. Contribuções à Geología Da Amazônia. Sociedade Brasileira de Geología, Núcleo Norte, Belém-Pará, pp. 15-90.

Dall'Agnol， R. (1992). Titanita-Biotita granitos Do Baixo Rio Uaupés, Província Rio Negro, Amazonas. Parte II: Geoquímica e petrogênese. Revista Brasileira de Geociências, 22(1), 15-28.

Domeier, M., and Torsvik, T.H. (2014). Plate tectonics in the late Paleozoic. Geoscience Frontiers, 5(3), 303-350. doi: 10.1016/j.gsf.2014.01.002.

Ernst, W.G. (2017). Earth's thermal evolution, mantle convection, and Hadean onset of plate tectonics. Journal of Asian Earth Sciences, 145(Part B), 334-348. doi: 10.1016/j.jseaes.2017.05.037.

Frost, B.R., Barnes, C.G., Collins, W.J., Arculus, R.J., Ellis, D.J., and Frost, C.D. (2001). A geochemical classification for granitic rocks. Journal of Petrology, 42(11), 2033-2048. doi: 10.1093/ petrology/42.11.2033.

Galvis, J. (1993). Los sedimentos precámbricos del Guainía y el origen de las ocurrencias auriferas en el Borde occidental del Escudo de Guayanas. Geología Colombiana, 18, 119-136.

Galvis, J., Huguett, A., y Ruge, P. (1979). Geología de la Amazonía Colombiana. Boletín Geológico, 22(3), 3-86.

Gansser, A. (1954). The Guiana Shield (S. America). Eclogae Geologicae Helvetiae, 47, 77-112.

Gansser, A. (1974). The Roraima Problem (South America). Verhandlungen der Naturforschenden Gesellschaften in Basel, 84(1), 80-100.

Gaudette, H.E., Mendoza, V., Hurley, P.M., and Fairbairn, H.W. (1978). Geology and age of the Parguaza rapakivi granite, Venezuela. GSA Bulletin, 89(9), 1335-1340. doi: 10.1130/0016-7606(1978)89<1335:GAAOTP $>2$. $0 . \mathrm{CO} ; 2$.
Gaudette, H., and Olszewski, W. (1985). Geochronology of the basement rocks, Amazonas Territory, Venezuela and Tectonic evolution of the western Guiana Shield. Geologie en Mijnbouw, 64(2), 131-143.

Geraldes, M., Van Schmus, W., Condie, K., Bell, S., Teixeira, W., and Babinski, M. (2001). Proterozoic geologic evolution of the SW part of the Amazonian Craton in Mato Grosso state, Brazil. Precambrian Research, 111(1-4), 91-128. doi: 10.1016/S0301-9268(01)00158-9.

Ghosh, S.K. (1985). Geology of the Roraima Group and its implications. I Simposium Amazonico. Puerto Ayacucho, Venezuela.

Gillespie, M.R., and Styles, M.T. (1999). Classification of igneous rocks. British Geological Survey Research Report, (2nd edition) RR 99-06, BGS Rock Classification Scheme Volume 1.

González-Iregui, H. (1989). Descripción petrográfica de las unidades litológicas de la Serranía Naquén (Colombia) y posibles correlaciones estratigráficas. $V$ Congreso Colombiano de Geología. Bucaramanga, Colombia.

Greber, N.D., Dauphas, N., Bekker, A., Ptáček, M.P., Bindeman, I.N., and Hofmann, A. (2017). Titanium isotopic evidence for felsic crust and plate tectonics 3.5 billion years ago. Science, 357(6357), 1271-1274. doi: 10.1126/science. aan8086.

Hill, R.I. (1993). Mantle plumes and continental tectonics. Lithos, 30(3-4), 193-206. doi: 10.1016/0024-4937(93)90035-B.

Ibañez, M. (2011). New U-Pb geochronological insights into the Proterozoic tectonic evolution of northwestern South America: the MesoNeoproterozoic Putumayo Orogen of Amazonia and implications for Rodinia reconstructions. MSc Thesis, Department of Geosciences, University of Arizona, USA.

Ibañez, M., Pullen, A., Arenstein, J., Gehrels, G.E., Valley, J., Ducea, M.N., Mora, A.R., Pecha, M., and Ruiz, J. (2015). Unraveling crustal growth and reworking processes in complex zircons from 
orogenic lower-crust: The Proterozoic Putumayo Orogen of Amazonia. Precambrian Research, 267, 285-310. doi: 10.1016/j.precamres.2015.06.014.

INGEOMINAS. (2006). Mapa geológico de Colombia a escala 1:2'800.000. Bogotá.

Jackson, S., Pearson, N., Griffin, W., and Belousova, E.A. (2004). The application of laser ablation-inductively coupled plasma-mass spectrometry to in situ U-Pb zircon geochronology. Chemical Geology, 211(12), 47-69. doi: 10.1016/j.chemgeo.2004.06.017.

Janoušek, V., Farrow, C.M., and Erban, V. (2006). Interpretation of whole-rock geochemical data in igneous geochemistry: Introducing Geochemical Data Toolkit (GCDkit). Journal of Petrology, 47(6), 1255-1259. doi: 10.1093/petrology/egl013.

Katzer, F. (1903). Grundzüge der Geologie des unteren Amazonasgebietes (des Staates Para in Brasilien). Leipzig: Max Weg.

López, J.A. (2012). Unidades, petrografía y composición química del Complejo Migmatítico de Mitú en los alrededores de Mitú: Réplica. Boletín de Geología, 34(1), 101-103.

López, J.A., Khurama, S., Bernal-Vargas, L.E., y Cuéllar, M.A. (2007). El Complejo Mitú: una nueva perspectiva. XI Congreso Colombiano de Geología. Bucaramanga.

Ludwig, K.R. (2003). Isoplot 3.00 - A Geochronological Toolkit for Microsoft Excel. Berkeley Geochronology Center.

Maitre, R.W. Le, Streckeisen, A., Zanettin, B., Bas, M.J. Le, Bonin, B., Bateman, P. (2002). Igneous Rocks: A classification and glossary of terms: Recommendations of the International Union of Geological Sciences Subcommission on the Systematics of Igneous Rocks. Cambridge: Cambridge University Press.

Maya-Sánchez, M. (2001). Distribución, facies y edad de las rocas metamórficas en Colombia. INGEOMINAS, Bogotá.

McMenamin, M.A.S., and McMenamin, D.L.S. (1990). The emergence of animals - The Cambrian Breakthrough. New York: Columbia University Press.
Meert, J.G., and Santosh, M. (2017). The Columbia supercontinent revisited. Gondwana Research, 50, 67-83. doi: 10.1016/j.gr.2017.04.011.

Mendoza, V.S. (2012). Geología de Venezuela. Bogotá: Editorial.

Ministerio das Minas e Energia. (1983). Mapa da Amazonia Legal 1: 2.500.000. Projeto Radambrasil, 2 hojas. Brasilia.

Montalvao, R. de, and Fernandes, P. (1975). Grupo Tunuí. Projeto RADAM. Relatório Inferno RADAM, 38-G, Belem.

Montgomery, C., and Hurley, P.M. (1978). Total rock $\mathrm{U}-\mathrm{Pb}$ and $\mathrm{Rb}-\mathrm{Sr}$ systematics in the Imataca series, Guayana Shield, Venezuela. Earth and Planetary Science Letters, 39(2), 281- 290. doi: 10.1016/0012-821X(78)90204-2.

Paiva, G. (1928). Reconhecimentos geológicos nas fronteiras do Brasil com Venezuela e Colômbia. Estado do Amazonas, Relatório An. Serv. Geol. Mineral. Río de Janeiro.

Petri, S., and Fulfaro, V. (1983). Geologia do Brasil (Fanerozóico). São Paulo: Universidade de São Paulo.

Pinheiro, S.S., Fernández, P.E.C.A., Pereira, E., Vasconcelos, E., Pinto, A., Montalvão, R.M., Issler, R., Dall'Agnol, R., Teixeira, W., and Fernández, C.A.C. (1976). Geología - Projeto Radar na Amazônia. Folha NA.19-Pico da Neblina. Levantamento de Recursos Naturais, 11, 19-137.

Piper, J.D.A. (2000). The Neoproterozoic Supercontinent: Rodinia or Palaeopangaea? Earth and Planetary Science Letters, 176(1), 131-146. doi: 10.1016/S0012-821X(99)00314-3.

Priem, H., Andriessen, P., Boelrijk, N., De Boorder, H., Hebeda, E., Huguett, A., Verdumen, E., and Verschure, R. (1982). Geochronology of the Precambrian in the Amazonas region of southeastern Colombia (western Guiana Shield). Geologie en Mijnbouw, 61(3), 229-242.

PRORADAM. (1979). La Amazonia Colombiana y sus recursos. Proyecto Radargramétrico Del Amazonas. Bogotá. 
Renzoni, G. (1989a). Comparación entre las secuencias metasedimentarias de la Serranía de Naquén y de la Serra da Jacobina. Boletín Geológico, 30(2), 25-42.

Renzoni, G. (1989b). La secuencia aurífera de la Serranía de Naquén. Boletín Geológico, 30(2), 43-103.

Rodríguez, G. (2012). Unidades, petrografía y composición química del Complejo Migmatítico de Mitú en los alrededores de Mitú: Respuesta. Boletín de Geología, 34(1), 105-107.

Rodríguez, G., Sepúlveda-Ospina, J., RamírezCardona, C., Ortiz-Párraga, F.H., Ramos-Carvajal, K., Bermúdez-Cordero, J.G., y Sierra-Rojas, M.I. (2011). Unidades, petrografía y composición química del Complejo Migmatítico de Mitú en los alrededores de Mitú. Boletín de Geología, 33(1), 27-42.

Rogers, J.J.W., and Santosh, M. (2002). Configuration of Columbia, a Mesoproterozoic Supercontinent. Gondwana Research, 5(1), 5-22. doi: 10.1016/ S1342-937X(05)70883-2.

Santos, J.O.S., Hartmann, L.A., Gaudette, H.E., Groves, D.I., Mcnaughton, N.J., and Fletcher, I.R. (2000). A new understanding of the provinces of the Amazon Craton based on integration of field mapping and $\mathrm{U}-\mathrm{Pb}$ and $\mathrm{Sm}-\mathrm{Nd}$ geochronology. Gondwana Research, 3(4), 453-488. doi: 10.1016/ S1342-937X(05)70755-3.

Santos, J.O.S., Potter, P.E., Reis, N.J., Hartmann, L.A., Fletcher, I.R., and McNaughton, N.J. (2003). Age, source, and regional stratigraphy of the Roraima Supergroup and Roraima-like outliers in northern South America based on U-Pb geochronology. GSA Bulletin, 115(3), 331-348. doi: 10.1130/0016-7606(2003)115<0331:ASAR $\mathrm{SO}>2.0 . \mathrm{CO} ; 2$.

Schobbenhaus, C., Campos, D. de A., Derze, G., and Asmus, H. (1984). Geologia do Brasil. Texto explicativo do mapa geologico do Brasil e da area oceanica adjacente incluiendo depositos minerais, escala 1:2.500.000. Departamento Nacional da Produção Mineral., Brasília.

Servicio Geológico Colombiano. (2015). Atlas Geológico de Colombia 2015. Bogotá.
Stern, R.J. (2005). Evidence from ophiolites, blueschists, and ultra-high pressure metamorphic terranes that the modern episode of subduction tectonics began in Neoproterozoic time. Geology, 33(7), 557-560. doi: 10.1130/G21365.1.

Stern, R.J., Leybourne, M.I., and Tsujimori, T. (2016). Kimberlites and the start of plate tectonics. Geology, 44(10), 799-802. doi: 10.1130/ G38024.1.

Streckeisen, A.L. (1967). Classification and nomenclature of igneous rocks (final report of an inquiry). Neues Jahrbuch fuer Mineralogie Abhandlungen, 107, 144-214.

Streckeisen, A. (1978). IUGS Subcommission on the Systematics of Igneous Rocks; classification and nomenclature of volcanic rocks, lamprophyres, carbonatites and melilitic rocks; recommendation and suggestions. Neues Jahrbuch fuer Mineraogie. Abhandlungen, 134, 1-14.

Tassinari, C.C.G., Cordani, U.G., Nutman, A.P., Van Schmus, W.R., Bettencourt, J.S., and Taylor, P.N. (1996). Geochronological systematics on basement rocks from the Río Negro-Juruena Province (Amazonian Craton) and tectonic implications. International Geology Review, 38(2), 161-175. doi: 10.1080/00206819709465329.

Tassinari, C.C.G., and Macambira, M.J.B. (1999). Geochronological provinces of the Amazonian Craton. Episodes, 22, 174-182.

Tassinari, C.G., and Macambira, J.B. (2004). A evolução tectônica do Craton Amazônico. In: V. Mantesso-Neto, A. Bartorelli, C. Carneiro, B. Brito-Neves (Eds.). Geología Do Continente Sul-Americano: Evolução Da Obra de Fernando Flávio Marques de Almeida (pp. 471-486). São Paulo: Editorial Beca.

Taylor, S.R., and McLennan, S.M. (1985). The Continental Crust: Its composition and evolution. Carlton: Blackwell Scientific Publications.

Teixeira, W., Geraldes, M.C., Matos, R., Ruiz, A.S., Saes, G., and Vargas-Mattos, G. (2010). A review of the tectonic evolution of the Sunsás belt, SW Amazonian Craton. Journal South American Earth Sciences, 29(1), 47-60. doi: 10.1016/j. jsames.2009.09.007. 
Teixeira, W., Tassinari, C.G., Cordani, U.G., and Kawashita, K. (1989). A review of the geochronology of the Amazonian Craton: Tectonic implications. Precambrian Research, 42(3-4), 213-227. doi: 10.1016/0301-9268(89)90012-0.

Thurston, P.C., and Fryer, B.J. (1983). The geochemistry of repetitive cyclical volcanism from basalt through rhyolite in the Uchi-Confederation Greenstone Belt, Canada. Contributions to Mineralogy and Petrology, 83(3-4), 204-226. doi: 10.1007/BF00371189.

Toussaint, J. (1993). Evolución Geológica de Colombia: Precámbrico, Paleozoico. Medellín: Universidad Nacional de Colombia.

Wilson, J.T. (1966). Did the Atlantic Close and then Re-Open?. Nature, 211, 676-681. doi: 10.1038/211676a0.

Yuen, D., Maruyama, S., Karato, S., and Windley, B. (2007). Superplumes: Beyond plate tectonics. Dordrecht: Springer.
Amed Bonilla

ORCID: 0000-0002-8961-7140

Thomas Cramer

ORCID: 0000-0002-7686-5241

Marc Poujol

ORCID: 0000-0001-8682-2926

Haroold Cano

ORCID: 0000-0003-2623-1686

José Alejandro Franco

ORCID: 0000-0003-4638-5885

Zeze Amaya

ORCID: 0000-0002-6832-9000

Trabajo recibido: noviembre 11 de 2017

Trabajo aceptado: agosto 22 de 2018 
ANEXO. Resultados isotópicos de U/Pb para las rocas aflorantes en el Rio Cuiarí. Cof_err= coeficiente de error.

\begin{tabular}{|c|c|c|c|c|c|c|c|c|c|c|c|c|c|c|c|c|}
\hline \multirow[b]{2}{*}{ Muestra } & \multirow[b]{2}{*}{ Analysis_\# } & \multicolumn{10}{|c|}{ Relaciones } & \multicolumn{5}{|c|}{ Edades } \\
\hline & & $\mathbf{T h} / \mathbf{U}$ & $207 / 235$ & $\begin{array}{l}1 \sigma \\
\text { err }\end{array}$ & $206 / 238$ & $1 \sigma \mathrm{err}$ & rho & $207 / 206$ & $\begin{array}{l}1 \sigma \\
\text { err }\end{array}$ & $207 / 206$ & $1 \sigma \mathrm{err}$ & $206 / 238$ & $\begin{array}{c}1 \sigma \\
\text { err }\end{array}$ & $207 / 235$ & $\begin{array}{c}1 \sigma \\
\text { err }\end{array}$ & $\begin{array}{c}\text { Conc } \\
\%\end{array}$ \\
\hline GU-403-135-A & 5190416 & 0,58 & 4,700 & 0,058 & 0,3174 & 0,0038 & 0,97 & 0,107 & 0,001 & 1756,1 & 19,2 & 1776,9 & 18,7 & 1767,3 & 10,4 & 100,6 \\
\hline GU-403-135-A & 6190416 & 0,77 & 4,717 & 0,058 & 0,3161 & 0,0038 & 0,98 & 0,108 & 0,001 & 1770,0 & 18,7 & 1770,6 & 18,6 & 1770,3 & 10,2 & 100,0 \\
\hline GU-403-135-A & 7190416 & 0,74 & 4,715 & 0,058 & 0,3166 & 0,0038 & 0,98 & 0,108 & 0,001 & 1766,4 & 19,0 & 1773,1 & 18,6 & 1770,0 & 10,3 & 100,2 \\
\hline GU-403-135-A & 8190416 & 0,79 & 4,694 & 0,057 & 0,3161 & 0,0038 & 0,98 & 0,108 & 0,001 & 1761,2 & 18,7 & 1770,6 & 18,6 & 1766,2 & 10,2 & 100,3 \\
\hline GU-403-135-A & 10190416 & 0,56 & 4,731 & 0,058 & 0,3169 & 0,0038 & 0,98 & 0,108 & 0,001 & 1770,5 & 18,9 & 1774,7 & 18,6 & 1772,7 & 10,3 & 100,1 \\
\hline GU-403-135-A & 11190416 & 0,75 & 4,770 & 0,059 & 0,3184 & 0,0038 & 0,97 & 0,109 & 0,001 & 1777,0 & 19,1 & 1781,9 & 18,7 & 1779,6 & 10,4 & 100,1 \\
\hline GU-403-135-A & 16190416 & 0,85 & 4,729 & 0,059 & 0,3172 & 0,0038 & 0,96 & 0,108 & 0,001 & 1768,0 & 19,3 & 1776,2 & 18,6 & 1772,4 & 10,4 & 100,2 \\
\hline GU-403-135-A & 17190416 & 0,97 & 4,723 & 0,058 & 0,3170 & 0,0038 & 0,97 & 0,108 & 0,001 & 1767,3 & 19,0 & 1774,9 & 18,6 & 1771,3 & 10,3 & 100,2 \\
\hline GU-403-135-A & 19190416 & 1,08 & 4,698 & 0,057 & 0,3170 & 0,0038 & 0,98 & 0,108 & 0,001 & 1757,4 & 18,8 & 1775,0 & 18,5 & 1766,8 & 10,2 & 100,5 \\
\hline GU-403-135-A & 21190416 & 0,69 & 4,737 & 0,058 & 0,3165 & 0,0038 & 0,97 & 0,109 & 0,001 & 1775,3 & 19,1 & 1772,8 & 18,5 & 1773,9 & 10,3 & 99,9 \\
\hline GU-403-135-A & 28190416 & 1,02 & 4,728 & 0,058 & 0,3160 & 0,0038 & 0,97 & 0,109 & 0,001 & 1775,0 & 19,2 & 1769,9 & 18,4 & 1772,2 & 10,3 & 99,8 \\
\hline GU-403-135-A & 29190416 & 0,88 & 4,721 & 0,058 & 0,3159 & 0,0038 & 0,97 & 0,108 & 0,001 & 1772,9 & 19,2 & 1769,4 & 18,4 & 1770,9 & 10,3 & 99,9 \\
\hline GU-403-135-A & 30190416 & 0,92 & 4,746 & 0,059 & 0,3161 & 0,0038 & 0,96 & 0,109 & 0,001 & 1781,2 & 19,2 & 1770,5 & 18,4 & 1775,3 & 10,3 & 99,7 \\
\hline GU-403-135-A & 31190416 & 1,11 & 4,775 & 0,059 & 0,3170 & 0,0038 & 0,96 & 0,109 & 0,001 & 1787,0 & 19,2 & 1775,2 & 18,5 & 1780,6 & 10,4 & 99,6 \\
\hline GU-403-135-A & 32190416 & 0,82 & 4,753 & 0,059 & 0,3169 & 0,0038 & 0,96 & 0,109 & 0,001 & 1779,4 & 19,4 & 1774,5 & 18,5 & 1776,7 & 10,4 & 99,8 \\
\hline GU-403-135-A & 33190416 & 0,72 & 4,721 & 0,059 & 0,3165 & 0,0038 & 0,96 & 0,108 & 0,001 & 1768,9 & 19,5 & 1772,8 & 18,5 & 1771,0 & 10,4 & 100,1 \\
\hline GU-403-135-A & 34190416 & 0,70 & 4,737 & 0,059 & 0,3160 & 0,0038 & 0,96 & 0,109 & 0,001 & 1778,7 & 19,4 & 1769,9 & 18,4 & 1773,9 & 10,4 & 99,7 \\
\hline GU-403-135-A & 38190416 & 0,72 & 4,716 & 0,058 & 0,3148 & 0,0037 & 0,96 & 0,109 & 0,001 & 1776,8 & 19,4 & 1764,5 & 18,3 & 1770,1 & 10,4 & 99,6 \\
\hline GU-403-135-A & 39190416 & 0,97 & 4,728 & 0,059 & 0,3172 & 0,0038 & 0,95 & 0,108 & 0,001 & 1768,2 & 19,7 & 1775,9 & 18,5 & 1772,3 & 10,5 & 100,2 \\
\hline GU-403-135-A & 40190416 & 0,64 & 4,769 & 0,059 & 0,3183 & 0,0038 & 0,96 & 0,109 & 0,001 & 1777,3 & 19,5 & 1781,5 & 18,5 & 1779,4 & 10,4 & 100,1 \\
\hline GU-403-135-A & 41190416 & 1,20 & 4,727 & 0,059 & 0,3162 & 0,0038 & 0,95 & 0,108 & 0,001 & 1773,5 & 19,6 & 1770,9 & 18,4 & 1772,0 & 10,4 & 99,9 \\
\hline GU-404-134 & 6210416 & 0,77 & 5,518 & 0,065 & 0,3422 & 0,0040 & 1,00 & 0,117 & 0,001 & 1910,0 & 18,0 & 1897,4 & 19,2 & 1903,4 & 10,1 & 99,7 \\
\hline GU-404-134 & 10210416 & 0,31 & 2,805 & 0,033 & 0,1961 & 0,0023 & 0,99 & 0,104 & 0,001 & 1692,4 & 18,5 & 1154,2 & 12,3 & 1356,8 & 8,8 & 80,2 \\
\hline GU-404-134 & 19210416 & 0,53 & 4,844 & 0,057 & 0,3167 & 0,0037 & 0,99 & 0,111 & 0,001 & 1814,9 & 18,4 & 1773,7 & 18,0 & 1792,6 & 9,9 & 98,8 \\
\hline GU-404-134 & 20210416 & 1,37 & 4,963 & 0,058 & 0,3138 & 0,0037 & 0,99 & 0,115 & 0,001 & 1875,4 & 18,3 & 1759,4 & 17,9 & 1813,0 & 9,9 & 96,7 \\
\hline GU-404-134 & 21210416 & 0,53 & 3,861 & 0,045 & 0,2461 & 0,0029 & 0,99 & 0,114 & 0,001 & 1861,4 & 18,3 & 1418,1 & 14,8 & 1605,6 & 9,5 & 86,3 \\
\hline GU-404-134 & 22210416 & 0,17 & 5,099 & 0,060 & 0,3218 & 0,0037 & 0,99 & 0,115 & 0,001 & 1879,1 & 18,3 & 1798,4 & 18,2 & 1836,0 & 10,0 & 97,7 \\
\hline GU-404-134 & 23210416 & 0,22 & 3,503 & 0,041 & 0,2367 & 0,0028 & 0,99 & 0,107 & 0,001 & 1754,6 & 18,5 & 1369,6 & 14,3 & 1527,8 & 9,3 & 87,1 \\
\hline GU-404-134 & 27210416 & 0,73 & 4,504 & 0,053 & 0,2966 & 0,0034 & 0,98 & 0,110 & 0,001 & 1801,7 & 18,6 & 1674,6 & 17,1 & 1731,8 & 9,8 & 96,1 \\
\hline GU-404-134 & 28210416 & 0,83 & 4,430 & 0,052 & 0,3034 & 0,0035 & 0,99 & 0,106 & 0,001 & 1730,0 & 18,7 & 1708,3 & 17,4 & 1718,0 & 9,8 & 99,3 \\
\hline GU-404-134 & 29210416 & 1,70 & 4,014 & 0,047 & 0,2691 & 0,0031 & 0,98 & 0,108 & 0,001 & 1769,1 & 18,7 & 1536,3 & 15,9 & 1637,0 & 9,6 & 92,5 \\
\hline GU-404-134 & 30210416 & 0,68 & 4,567 & 0,054 & 0,2944 & 0,0034 & 0,98 & 0,113 & 0,001 & 1841,0 & 18,6 & 1663,2 & 17,0 & 1743,3 & 9,8 & 94,7 \\
\hline GU-404-134 & 31210416 & 0,65 & 4,993 & 0,059 & 0,3125 & 0,0036 & 0,98 & 0,116 & 0,001 & 1894,2 & 18,4 & 1752,7 & 17,8 & 1818,2 & 10,0 & 96,0 \\
\hline GU-404-134 & 32210416 & 0,49 & 4,440 & 0,053 & 0,2895 & 0,0034 & 0,98 & 0,111 & 0,001 & 1819,7 & 18,7 & 1639,1 & 16,8 & 1719,8 & 9,8 & 94,5 \\
\hline GU-404-134 & 33210416 & 0,35 & 4,586 & 0,054 & 0,2889 & 0,0034 & 0,98 & 0,115 & 0,001 & 1882,4 & 18,5 & 1635,9 & 16,8 & 1746,8 & 9,9 & 92,8 \\
\hline GU-404-134 & 34210416 & 0,42 & 4,948 & 0,059 & 0,3262 & 0,0038 & 0,98 & 0,110 & 0,001 & 1800,1 & 18,7 & 1819,8 & 18,4 & 1810,5 & 10,0 & 100,6 \\
\hline GU-404-134 & 38210416 & 1,90 & 4,708 & 0,056 & 0,2878 & 0,0033 & 0,97 & 0,119 & 0,001 & 1936,3 & 18,5 & 1630,6 & 16,7 & 1768,7 & 10,0 & 91,3 \\
\hline GU-404-134 & 40210416 & 0,45 & 4,690 & 0,056 & 0,3085 & 0,0036 & 0,97 & 0,110 & 0,001 & 1804,0 & 18,9 & 1733,1 & 17,6 & 1765,4 & 10,0 & 97,9 \\
\hline GU-404-133 & 5210416 & 0,69 & 4,681 & 0,056 & 0,3136 & 0,0037 & 0,99 & 0,108 & 0,001 & 1770,2 & 18,6 & 1758,6 & 18,1 & 1763,9 & 10,0 & 99,6 \\
\hline GU-404-133 & 6210416 & 0,59 & 4,672 & 0,056 & 0,3151 & 0,0037 & 0,99 & 0,108 & 0,001 & 1758,3 & 18,5 & 1765,9 & 18,2 & 1762,3 & 10,0 & 100,2 \\
\hline GU-404-133 & 7210416 & 0,57 & 4,672 & 0,056 & 0,3140 & 0,0037 & 0,99 & 0,108 & 0,001 & 1764,6 & 18,5 & 1760,4 & 18,1 & 1762,3 & 10,0 & 99,9 \\
\hline GU-404-133 & 8210416 & 0,71 & 4,681 & 0,056 & 0,3147 & 0,0037 & 0,99 & 0,108 & 0,001 & 1764,2 & 18,6 & 1763,6 & 18,2 & 1763,8 & 10,0 & 100,0 \\
\hline GU-404-133 & 9210416 & 0,56 & 4,728 & 0,056 & 0,3166 & 0,0037 & 0,99 & 0,108 & 0,001 & 1771,7 & 18,7 & 1772,8 & 18,2 & 1772,3 & 10,0 & 100,0 \\
\hline GU-404-133 & 10210416 & 0,72 & 4,692 & 0,056 & 0,3170 & 0,0037 & 0,99 & 0,107 & 0,001 & 1755,0 & 18,6 & 1775,0 & 18,2 & 1765,8 & 10,0 & 100,6 \\
\hline GU-404-133 & 11210416 & 0,67 & 4,645 & 0,055 & 0,3135 & 0,0037 & 0,99 & 0,107 & 0,001 & 1756,8 & 18,6 & 1758,1 & 18,1 & 1757,5 & 9,9 & 100,0 \\
\hline GU-404-133 & 16210416 & 0,70 & 4,693 & 0,056 & 0,3151 & 0,0037 & 0,98 & 0,108 & 0,001 & 1766,4 & 18,7 & 1765,8 & 18,1 & 1766,1 & 10,0 & 100,0 \\
\hline GU-404-133 & 17210416 & 0,59 & 4,745 & 0,057 & 0,3153 & 0,0037 & 0,98 & 0,109 & 0,001 & 1785,6 & 18,7 & 1766,5 & 18,1 & 1775,2 & 10,0 & 99,4 \\
\hline GU-404-133 & 18210416 & 0,65 & 4,693 & 0,056 & 0,3150 & 0,0037 & 0,99 & 0,108 & 0,001 & 1766,9 & 18,7 & 1765,3 & 18,1 & 1766,0 & 10,0 & 99,9 \\
\hline
\end{tabular}




\begin{tabular}{|c|c|c|c|c|c|c|c|c|c|c|c|c|c|c|c|c|}
\hline \multirow[b]{2}{*}{ Muestra } & \multirow[b]{2}{*}{ Analysis_\# } & \multicolumn{10}{|c|}{ Relaciones } & \multicolumn{5}{|c|}{ Edades } \\
\hline & & $\mathrm{Th} / \mathrm{U}$ & 207/235 & $\begin{array}{l}1 \sigma \\
\text { err }\end{array}$ & $206 / 238$ & $1 \sigma \mathrm{err}$ & rho & 207/206 & $\begin{array}{l}1 \sigma \\
\text { err }\end{array}$ & 207/206 & $1 \sigma \mathrm{err}$ & 206/238 & $\begin{array}{c}1 \sigma \\
\text { err }\end{array}$ & 207/235 & $\begin{array}{l}1 \sigma \\
\text { err }\end{array}$ & $\begin{array}{c}\text { Conc } \\
\%\end{array}$ \\
\hline GU-404-133 & 20210416 & 0,64 & 4,698 & 0,056 & 0,3153 & 0,0037 & 0,98 & 0,108 & 0,001 & 1766,9 & 18,9 & 1766,9 & 18,1 & 1766,9 & 10,0 & 100,0 \\
\hline GU-404-133 & 21210416 & 0,64 & 4,676 & 0,056 & 0,3146 & 0,0037 & 0,98 & 0,108 & 0,001 & 1762,3 & 18,7 & 1763,5 & 18,0 & 1762,9 & 10,0 & 100,0 \\
\hline GU-404-133 & 22210416 & 0,62 & 4,725 & 0,056 & 0,3165 & 0,0037 & 0,98 & 0,108 & 0,001 & 1770,6 & 18,9 & 1772,6 & 18,1 & 1771,6 & 10,0 & 100,1 \\
\hline GU-404-133 & 23210416 & 0,76 & 4,759 & 0,057 & 0,3148 & 0,0037 & 0,98 & 0,110 & 0,001 & 1793,2 & 18,9 & 1764,5 & 18,0 & 1777,6 & 10,0 & 99,1 \\
\hline GU-404-133 & 28210416 & 0,62 & 4,683 & 0,056 & 0,3153 & 0,0037 & 0,97 & 0,108 & 0,001 & 1761,2 & 19,0 & 1766,8 & 18,0 & 1764,2 & 10,0 & 100,2 \\
\hline GU-404-133 & 29210416 & 0,56 & 4,671 & 0,056 & 0,3147 & 0,0037 & 0,97 & 0,108 & 0,001 & 1760,2 & 19,0 & 1763,8 & 18,0 & 1762,1 & 10,0 & 100,1 \\
\hline GU-404-133 & 30210416 & 0,55 & 4,724 & 0,057 & 0,3164 & 0,0037 & 0,97 & 0,108 & 0,001 & 1770,9 & 19,1 & 1772,1 & 18,0 & 1771,5 & 10,0 & 100,0 \\
\hline GU-404-133 & 31210416 & 0,78 & 4,694 & 0,056 & 0,3158 & 0,0037 & 0,97 & 0,108 & 0,001 & 1762,8 & 19,1 & 1769,3 & 18,0 & 1766,2 & 10,0 & 100,2 \\
\hline GU-404-133 & 34210416 & 0,73 & 4,715 & 0,057 & 0,3148 & 0,0037 & 0,97 & 0,109 & 0,001 & 1777,1 & 19,2 & 1764,1 & 17,9 & 1770,0 & 10,1 & 99,6 \\
\hline GU-404-133 & 38210416 & 0,61 & 4,707 & 0,057 & 0,3155 & 0,0037 & 0,96 & 0,108 & 0,001 & 1769,9 & 19,4 & 1767,5 & 17,9 & 1768,5 & 10,1 & 99,9 \\
\hline GU-404-133 & 39210416 & 0,56 & 4,723 & 0,057 & 0,3153 & 0,0037 & 0,96 & 0,109 & 0,001 & 1777,3 & 19,4 & 1766,5 & 17,9 & 1771,4 & 10,1 & 99,7 \\
\hline GU-404-133 & 40210416 & 0,78 & 4,695 & 0,057 & 0,3155 & 0,0037 & 0,96 & 0,108 & 0,001 & 1765,1 & 19,4 & 1767,7 & 17,9 & 1766,4 & 10,1 & 100,1 \\
\hline GU-404-133 & 41210416 & 0,64 & 4,673 & 0,056 & 0,3150 & 0,0036 & 0,96 & 0,108 & 0,001 & 1759,3 & 19,4 & 1765,3 & 17,9 & 1762,4 & 10,1 & 100,2 \\
\hline GU-404-130 & 6210416 & 0,76 & 4,692 & 0,054 & 0,3148 & 0,0036 & 0,99 & 0,108 & 0,001 & 1767,4 & 18,5 & 1764,5 & 17,64 & 1765,7 & 9,65 & 99,9 \\
\hline GU-404-130 & 7210416 & 0,88 & 4,683 & 0,054 & 0,3152 & 0,0036 & 0,99 & 0,108 & 0,001 & 1761,7 & 18,39 & 1766,5 & 17,68 & 1764,2 & 9,64 & 100,1 \\
\hline GU-404-130 & 8210416 & 0,91 & 4,656 & 0,054 & 0,3145 & 0,0036 & 0,99 & 0,107 & 0,001 & 1755,5 & 18,65 & 1762,9 & 17,69 & 1759,4 & 9,74 & 100,2 \\
\hline GU-404-130 & 10210416 & 0,77 & 4,698 & 0,055 & 0,3155 & 0,0036 & 0,99 & 0,108 & 0,001 & 1766,3 & 18,73 & 1767,5 & 17,77 & 1766,9 & 9,78 & 100,0 \\
\hline GU-404-130 & 16210416 & 1,07 & 4,706 & 0,055 & 0,3160 & 0,0037 & 0,98 & 0,108 & 0,001 & 1765,9 & 18,72 & 1770,3 & 17,9 & 1768,2 & 9,83 & 100,1 \\
\hline GU-404-130 & 19210416 & 1,10 & 4,699 & 0,055 & 0,3159 & 0,0037 & 0,98 & 0,108 & 0,001 & 1764,2 & 18,66 & 1769,7 & 17,95 & 1767,1 & 9,87 & 100,2 \\
\hline GU-404-130 & 20210416 & 0,86 & 4,680 & 0,055 & 0,3156 & 0,0037 & 0,99 & 0,108 & 0,001 & 1758,2 & 18,65 & 1768,4 & 17,96 & 1763,6 & 9,87 & 100,3 \\
\hline GU-404-130 & 22210416 & 0,77 & 4,689 & 0,056 & 0,3159 & 0,0037 & 0,98 & 0,108 & 0,001 & 1760 & 18,79 & 1769,8 & 18,02 & 1765,2 & 9,95 & 100,3 \\
\hline GU-404-130 & 27210416 & 0,54 & 4,734 & 0,057 & 0,3168 & 0,0037 & 0,97 & 0,108 & 0,001 & 1772,6 & 19,02 & 1773,8 & 18,16 & 1773,2 & 10,08 & 100,0 \\
\hline GU-404-130 & 28210416 & 1,11 & 4,684 & 0,056 & 0,3161 & 0,0037 & 0,98 & 0,107 & 0,001 & 1757,2 & 18,93 & 1770,7 & 18,15 & 1764,5 & 10,06 & 100,4 \\
\hline GU-404-130 & 30210416 & 1,05 & 4,693 & 0,057 & 0,3163 & 0,0037 & 0,97 & 0,108 & 0,001 & 1759,2 & 18,98 & 1771,8 & 18,2 & 1766 & 10,1 & 100,4 \\
\hline GU-404-130 & 32210416 & 0,81 & 4,724 & 0,057 & 0,3162 & 0,0037 & 0,98 & 0,108 & 0,001 & 1772,3 & 18,96 & 1771 & 18,23 & 1771,5 & 10,11 & 100,0 \\
\hline GU-404-130 & 33210416 & 0,79 & 4,724 & 0,057 & 0,3165 & 0,0037 & 0,97 & 0,108 & 0,001 & 1770,1 & 19,06 & 1772,8 & 18,27 & 1771,5 & 10,15 & 100,1 \\
\hline GU-404-130 & 34210416 & 1,12 & 4,674 & 0,057 & 0,3164 & 0,0037 & 0,97 & 0,107 & 0,001 & 1751,7 & 19 & 1772 & 18,28 & 1762,6 & 10,15 & 100,6 \\
\hline GU-404-130 & 38210416 & 0,33 & 4,667 & 0,057 & 0,3162 & 0,0038 & 0,97 & 0,107 & 0,001 & 1749,9 & 19,01 & 1771,1 & 18,35 & 1761,3 & 10,19 & 100,7 \\
\hline GU-404-130 & 39210416 & 0,74 & 4,726 & 0,058 & 0,3171 & 0,0038 & 0,96 & 0,108 & 0,001 & 1767,7 & 19,44 & 1775,6 & 18,44 & 1771,9 & 10,36 & 100,2 \\
\hline GU-404-130 & 41210416 & 0,87 & 4,669 & 0,058 & 0,3157 & 0,0038 & 0,96 & 0,107 & 0,001 & 1753,9 & 19,27 & 1768,5 & 18,4 & 1761,7 & 10,33 & 100,4 \\
\hline GU-403-125 & 5210416 & 0,13 & 1,520 & 0,018 & 0,1192 & 0,0014 & 0,99 & 0,092 & 0,001 & 1477,3 & 19,3 & 726,0 & 8,0 & 938,4 & 7,2 & 63,5 \\
\hline GU-403-125 & 6210416 & 0,26 & 3,629 & 0,043 & 0,2187 & 0,0025 & 0,98 & 0,120 & 0,001 & 1961,7 & 18,2 & 1274,8 & 13,5 & 1555,8 & 9,4 & 79,3 \\
\hline GU-403-125 & 7210416 & 0,77 & 2,995 & 0,035 & 0,1833 & 0,0021 & 0,99 & 0,119 & 0,001 & 1934,1 & 18,1 & 1084,9 & 11,6 & 1406,3 & 8,9 & 72,7 \\
\hline GU-403-125 & 8210416 & 0,04 & 3,784 & 0,044 & 0,2558 & 0,0030 & 0,99 & 0,107 & 0,001 & 1754,1 & 18,4 & 1468,3 & 15,3 & 1589,3 & 9,4 & 90,6 \\
\hline GU-403-125 & 10210416 & 1,40 & 4,689 & 0,055 & 0,3056 & 0,0036 & 0,98 & 0,111 & 0,001 & 1820,8 & 18,5 & 1719,1 & 17,6 & 1765,4 & 9,9 & 97,0 \\
\hline GU-403-125 & 16210416 & 0,64 & 4,725 & 0,056 & 0,3144 & 0,0037 & 0,98 & 0,109 & 0,001 & 1783,1 & 18,8 & 1762,2 & 17,9 & 1771,7 & 9,9 & 99,4 \\
\hline GU-403-125 & 17210416 & 0,04 & 3,431 & 0,040 & 0,2418 & 0,0028 & 0,99 & 0,103 & 0,001 & 1677,7 & 18,7 & 1396,0 & 14,6 & 1511,6 & 9,2 & 90,1 \\
\hline GU-403-125 & 18210416 & 0,06 & 2,451 & 0,029 & 0,1797 & 0,0021 & 0,99 & 0,099 & 0,001 & 1603,7 & 18,9 & 1065,6 & 11,4 & 1257,7 & 8,4 & 78,4 \\
\hline GU-403-125 & 19210416 & 0,49 & 2,910 & 0,034 & 0,1821 & 0,0021 & 0,98 & 0,116 & 0,001 & 1894,6 & 18,5 & 1078,1 & 11,5 & 1384,5 & 8,9 & 73,1 \\
\hline GU-403-125 & 21210416 & 0,10 & 2,410 & 0,028 & 0,1767 & 0,0021 & 0,99 & 0,099 & 0,001 & 1603,3 & 18,9 & 1049,1 & 11,2 & 1245,5 & 8,4 & 77,7 \\
\hline GU-403-125 & 22210416 & 0,49 & 3,343 & 0,040 & 0,2135 & 0,0025 & 0,98 & 0,114 & 0,001 & 1857,7 & 18,7 & 1247,3 & 13,2 & 1491,2 & 9,3 & 80,3 \\
\hline GU-403-125 & 23210416 & 0,26 & 1,925 & 0,023 & 0,1146 & 0,0013 & 0,97 & 0,122 & 0,001 & 1983,7 & 18,8 & 699,3 & 7,7 & 1089,9 & 8,0 & 54,9 \\
\hline GU-403-125 & 27210416 & 0,06 & 2,779 & 0,033 & 0,2004 & 0,0023 & 0,98 & 0,101 & 0,001 & 1634,3 & 19,0 & 1177,7 & 12,5 & 1349,8 & 8,8 & 82,6 \\
\hline GU-403-125 & 28210416 & 0,95 & 4,439 & 0,053 & 0,2913 & 0,0034 & 0,97 & 0,111 & 0,001 & 1808,0 & 19,1 & 1648,1 & 16,9 & 1719,6 & 10,0 & 95,1 \\
\hline GU-403-125 & 29210416 & 0,68 & 4,055 & 0,049 & 0,2712 & 0,0032 & 0,96 & 0,108 & 0,001 & 1773,8 & 19,4 & 1546,9 & 16,0 & 1645,4 & 9,8 & 92,8 \\
\hline GU-403-125 & 30210416 & 0,02 & 2,000 & 0,024 & 0,1453 & 0,0017 & 0,98 & 0,100 & 0,001 & 1620,6 & 19,1 & 874,8 & 9,5 & 1115,5 & 8,0 & 68,8 \\
\hline GU-403-125 & 32210416 & 0,85 & 4,565 & 0,054 & 0,2808 & 0,0033 & 0,98 & 0,118 & 0,001 & 1924,7 & 18,6 & 1595,6 & 16,4 & 1742,9 & 9,9 & 90,6 \\
\hline GU-403-125 & 34210416 & 0,92 & 3,510 & 0,043 & 0,2157 & 0,0025 & 0,96 & 0,118 & 0,001 & 1926,9 & 19,1 & 1258,9 & 13,3 & 1529,4 & 9,6 & 79,4 \\
\hline GU-403-125 & 38210416 & 0,51 & 4,766 & 0,058 & 0,3099 & 0,0036 & 0,95 & 0,112 & 0,001 & 1824,5 & 19,6 & 1740,4 & 17,7 & 1778,9 & 10,3 & 97,5 \\
\hline GU-403-125 & 39210416 & 1,08 & 4,640 & 0,056 & 0,3100 & 0,0036 & 0,96 & 0,109 & 0,001 & 1775,4 & 19,3 & 1740,9 & 17,7 & 1756,6 & 10,0 & 98,9 \\
\hline GU-403-125 & 40210416 & 0,06 & 1,548 & 0,018 & 0,1288 & 0,0015 & 0,97 & 0,087 & 0,001 & 1363,9 & 20,0 & 781,2 & 8,5 & 949,7 & 7,3 & 69,6 \\
\hline GU-403-125 & 41210416 & 0,09 & 2,759 & 0,033 & 0,1891 & 0,0022 & 0,97 & 0,106 & 0,001 & 1728,6 & 19,1 & 1116,5 & 11,9 & 1344,4 & 8,9 & 77,8 \\
\hline GU-403-124 & 5190416 & 0,48 & 3,898 & 0,047 & 0,2601 & 0,0030 & 0,96 & 0,109 & 0,001 & 1778,4 & 19,4 & 1490,1 & 15,3 & 1613,3 & 9,7 & 90,7 \\
\hline GU-403-124 & 7190416 & 0,38 & 1,858 & 0,022 & 0,1253 & 0,0014 & 0,96 & 0,108 & 0,001 & 1759,6 & 19,4 & 760,8 & 8,2 & 1066,4 & 7,9 & 60,6 \\
\hline
\end{tabular}




\begin{tabular}{|c|c|c|c|c|c|c|c|c|c|c|c|c|c|c|c|c|}
\hline \multirow[b]{2}{*}{ Muestra } & \multirow[b]{2}{*}{ Analysis_\# } & \multicolumn{10}{|c|}{ Relaciones } & \multicolumn{5}{|c|}{ Edades } \\
\hline & & $T h / U$ & $207 / 235$ & $\begin{array}{l}1 \sigma \\
\text { err }\end{array}$ & $206 / 238$ & $1 \sigma \mathrm{err}$ & rho & $207 / 206$ & $\begin{array}{l}1 \sigma \\
\text { err }\end{array}$ & $207 / 206$ & $1 \sigma$ err & $206 / 238$ & $\begin{array}{l}1 \sigma \\
\text { err }\end{array}$ & $207 / 235$ & $\begin{array}{l}1 \sigma \\
\text { err }\end{array}$ & $\begin{array}{c}\text { Conc } \\
\%\end{array}$ \\
\hline GU-403-124 & 8190416 & 0,65 & 4,461 & 0,054 & 0,3008 & 0,0035 & 0,96 & 0,108 & 0,001 & 1758,9 & 19,3 & 1695,3 & 17,1 & 1723,8 & 10,0 & 98,0 \\
\hline GU-403-124 & 9190416 & 0,27 & 1,992 & 0,024 & 0,1336 & 0,0015 & 0,94 & 0,108 & 0,001 & 1768,0 & 19,8 & 808,6 & 8,8 & 1112,8 & 8,3 & 62,9 \\
\hline GU-403-124 & 10190416 & 0,36 & 3,809 & 0,045 & 0,2546 & 0,0029 & 0,97 & 0,109 & 0,001 & 1774,8 & 19,1 & 1462,2 & 15,1 & 1594,7 & 9,6 & 89,9 \\
\hline GU-403-124 & 11190416 & 0,23 & 1,163 & 0,014 & 0,0769 & 0,0009 & 0,94 & 0,11 & 0,001 & 1795,2 & 19,8 & 477,3 & 5,3 & 783,3 & 6,7 & 43,6 \\
\hline GU-403-124 & 16190416 & 0,71 & 2,767 & 0,034 & 0,1848 & 0,0022 & 0,95 & 0,109 & 0,001 & 1776,7 & 19,6 & 1093,0 & 11,7 & 1346,8 & 9,1 & 75,8 \\
\hline GU-403-124 & 17190416 & 0,53 & 3,789 & 0,046 & 0,2567 & 0,0030 & 0,95 & 0,107 & 0,001 & 1750,3 & 19,5 & 1472,7 & 15,3 & 1590,4 & 9,8 & 90,9 \\
\hline GU-403-124 & 18190416 & 0,44 & 4,045 & 0,049 & 0,2644 & 0,0031 & 0,96 & 0,111 & 0,001 & 1815,3 & 19,1 & 1512,2 & 15,7 & 1643,3 & 9,8 & 90,5 \\
\hline GU-403-124 & 19190416 & 0,94 & 4,126 & 0,050 & 0,2732 & 0,0032 & 0,97 & 0,11 & 0,001 & 1791,9 & 19,1 & 1556,8 & 16,1 & 1659,4 & 9,9 & 92,6 \\
\hline GU-403-124 & 20190416 & 0,91 & 3,909 & 0,047 & 0,2622 & 0,0031 & 0,96 & 0,108 & 0,001 & 1768,2 & 19,3 & 1501,0 & 15,6 & 1615,5 & 9,8 & 91,4 \\
\hline GU-403-124 & 22190416 & 1,06 & 4,231 & 0,052 & 0,2782 & 0,0033 & 0,95 & 0,11 & 0,001 & 1804,2 & 19,5 & 1582,5 & 16,4 & 1680,1 & 10,1 & 93,1 \\
\hline GU-403-124 & 23190416 & 0,31 & 2,640 & 0,032 & 0,1794 & 0,0021 & 0,96 & 0,107 & 0,001 & 1743,9 & 19,3 & 1063,8 & 11,5 & 1311,7 & 8,9 & 75,2 \\
\hline GU-403-124 & 27190416 & 0,80 & 2,510 & 0,031 & 0,1687 & 0,0020 & 0,96 & 0,108 & 0,001 & 1765,1 & 19,5 & 1004,7 & 11,0 & 1275,0 & 9,0 & 72,2 \\
\hline GU-403-124 & 28190416 & 0,53 & 4,704 & 0,060 & 0,3120 & 0,0037 & 0,93 & 0,109 & 0,001 & 1788,7 & 20,2 & 1750,3 & 18,2 & 1767,9 & 10,6 & 98,8 \\
\hline GU-403-124 & 29190416 & 0,23 & 1,759 & 0,022 & 0,1270 & 0,0015 & 0,94 & 0,101 & 0,001 & 1633,8 & 20,4 & 770,4 & 8,6 & 1030,6 & 8,2 & 63,1 \\
\hline GU-403-124 & 30190416 & 0,50 & 4,598 & 0,057 & 0,3124 & 0,0037 & 0,95 & 0,107 & 0,001 & 1744,5 & 19,7 & 1752,6 & 18,2 & 1748,9 & 10,4 & 100,3 \\
\hline GU-403-124 & 31190416 & 0,62 & 4,664 & 0,059 & 0,3139 & 0,0037 & 0,93 & 0,108 & 0,001 & 1762,3 & 20,2 & 1759,8 & 18,3 & 1760,9 & 10,6 & 99,9 \\
\hline GU-403-124 & 32190416 & 0,57 & 4,597 & 0,058 & 0,3125 & 0,0037 & 0,94 & 0,107 & 0,001 & 1743,6 & 19,9 & 1753,0 & 18,2 & 1748,7 & 10,5 & 100,3 \\
\hline GU-403-124 & 34190416 & 0,62 & 4,608 & 0,059 & 0,3126 & 0,0037 & 0,93 & 0,107 & 0,001 & 1747,5 & 20,4 & 1753,7 & 18,3 & 1750,8 & 10,7 & 100,2 \\
\hline GU-403-124 & 38190416 & 0,74 & 4,626 & 0,061 & 0,3120 & 0,0038 & 0,91 & 0,108 & 0,001 & 1758,5 & 21,0 & 1750,3 & 18,4 & 1754,0 & 11,0 & 99,7 \\
\hline GU-403-124 & 40190416 & 0,39 & 2,625 & 0,034 & 0,1781 & 0,0021 & 0,93 & 0,107 & 0,001 & 1747,4 & 20,3 & 1056,5 & 11,7 & 1307,6 & 9,5 & 74,8 \\
\hline GU-403-124 & 41190416 & 0,61 & 4,615 & 0,061 & 0,3130 & 0,0038 & 0,91 & 0,107 & 0,001 & 1748,1 & 20,9 & 1755,3 & 18,5 & 1751,9 & 11,0 & 100,2 \\
\hline GU-403-123 & 5200416 & 0,38 & 3,498 & 0,041 & 0,2669 & 0,0031 & 0,98 & 0,095 & 0,001 & 1529,3 & 19,5 & 1525,2 & 15,7 & 1526,8 & 9,3 & 99,8 \\
\hline GU-403-123 & 7200416 & 0,68 & 2,614 & 0,031 & 0,2242 & 0,0026 & 0,97 & 0,085 & 0,001 & 1306,2 & 20,2 & 1303,8 & 13,6 & 1304,7 & 8,7 & 99,9 \\
\hline GU-403-123 & 8200416 & 0,09 & 2,005 & 0,023 & 0,1886 & 0,0022 & 0,99 & 0,077 & 0,001 & 1124,1 & 20,3 & 1113,8 & 11,8 & 1117,2 & 7,9 & 99,4 \\
\hline GU-403-123 & 9200416 & 0,57 & 3,462 & 0,043 & 0,2664 & 0,0031 & 0,94 & 0,094 & 0,001 & 1513,7 & 20,8 & 1522,2 & 15,8 & 1518,6 & 9,8 & 100,3 \\
\hline GU-403-123 & 10200416 & 0,75 & 3,460 & 0,042 & 0,2673 & 0,0031 & 0,95 & 0,094 & 0,001 & 1506,4 & 20,2 & 1526,8 & 15,8 & 1518,2 & 9,6 & 100,8 \\
\hline GU-403-123 & 11200416 & 0,95 & 4,984 & 0,059 & 0,3270 & 0,0038 & 0,98 & 0,111 & 0,001 & 1808,3 & 18,6 & 1823,9 & 18,4 & 1816,6 & 10,0 & 100,5 \\
\hline GU-403-123 & 12200416 & 0,39 & 3,579 & 0,042 & 0,2704 & 0,0031 & 0,98 & 0,096 & 0,001 & 1548,1 & 19,3 & 1542,8 & 15,9 & 1545,0 & 9,4 & 99,8 \\
\hline GU-403-123 & 16200416 & 0,66 & 5,004 & 0,059 & 0,3269 & 0,0038 & 0,98 & 0,111 & 0,001 & 1816,4 & 18,5 & 1823,2 & 18,5 & 1820,0 & 10,0 & 100,2 \\
\hline GU-403-123 & 17200416 & 0,69 & 5,005 & 0,060 & 0,3274 & 0,0038 & 0,98 & 0,111 & 0,001 & 1813,9 & 18,7 & 1825,8 & 18,5 & 1820,2 & 10,1 & 100,3 \\
\hline GU-403-123 & 18200416 & 0,22 & 5,246 & 0,062 & 0,3380 & 0,0039 & 0,99 & 0,113 & 0,001 & 1841,4 & 18,4 & 1877,0 & 19,0 & 1860,1 & 10,1 & 101,0 \\
\hline GU-403-123 & 19200416 & 0,70 & 4,996 & 0,060 & 0,3274 & 0,0038 & 0,98 & 0,111 & 0,001 & 1810,2 & 18,7 & 1826,0 & 18,6 & 1818,6 & 10,1 & 100,5 \\
\hline GU-403-123 & 20200416 & 0,34 & 2,029 & 0,025 & 0,1876 & 0,0022 & 0,96 & 0,078 & 0,001 & 1158,9 & 20,9 & 1108,2 & 11,9 & 1125,4 & 8,3 & 97,1 \\
\hline GU-403-123 & 21200416 & 0,41 & 3,442 & 0,041 & 0,2664 & 0,0031 & 0,97 & 0,094 & 0,001 & 1502,3 & 19,7 & 1522,6 & 15,9 & 1514,0 & 9,5 & 100,8 \\
\hline GU-403-123 & 22200416 & 0,47 & 2,697 & 0,032 & 0,2285 & 0,0027 & 0,98 & 0,086 & 0,001 & 1329,3 & 20,1 & 1326,7 & 14,0 & 1327,6 & 8,9 & 99,9 \\
\hline GU-403-123 & 23200416 & 0,33 & 1,749 & 0,021 & 0,1739 & 0,0020 & 0,97 & 0,073 & 0,001 & 1012,1 & 21,2 & 1033,6 & 11,2 & 1026,7 & 7,8 & 101,4 \\
\hline GU-403-123 & 27200416 & 0,60 & 3,741 & 0,045 & 0,2775 & 0,0033 & 0,97 & 0,098 & 0,001 & 1582,7 & 19,6 & 1578,5 & 16,5 & 1580,2 & 9,7 & 99,8 \\
\hline GU-403-123 & 28200416 & 0,90 & 4,989 & 0,060 & 0,3290 & 0,0039 & 0,98 & 0,110 & 0,001 & 1799,3 & 18,8 & 1833,3 & 18,8 & 1817,4 & 10,2 & 101,0 \\
\hline GU-403-123 & 29200416 & 0,42 & 3,337 & 0,042 & 0,2597 & 0,0031 & 0,95 & 0,093 & 0,001 & 1491,5 & 20,5 & 1488,5 & 15,7 & 1489,6 & 9,7 & 99,9 \\
\hline GU-403-123 & 31200416 & 0,91 & 3,486 & 0,043 & 0,2669 & 0,0032 & 0,95 & 0,095 & 0,001 & 1523,1 & 20,2 & 1524,9 & 16,1 & 1524,1 & 9,8 & 100,1 \\
\hline GU-403-123 & 32200416 & 0,59 & 1,782 & 0,022 & 0,1735 & 0,0021 & 0,95 & 0,075 & 0,001 & 1055,1 & 22,0 & 1031,3 & 11,3 & 1039,0 & 8,1 & 98,5 \\
\hline GU-403-123 & 200416 & 0,24 & 3,796 & 0,046 & 774 & 0,0033 & 0,98 & 0,099 & 0,001 & 1610,3 & 19,3 & 1578,3 & 16,5 & 1592,0 & 9,7 & 98,9 \\
\hline GU-403-123 & 38200416 & 0,40 & 2,024 & 0,027 & 0,1871 & 0,0022 & 0,90 & 0,078 & 0,001 & 1158,6 & 23,1 & 1105,6 & 12,2 & 1123,5 & 9,0 & 97,0 \\
\hline GU-403-123 & 40200416 & 0,72 & 5,008 & 0,061 & 0,3274 & 0,0039 & 0,97 & 0,111 & 0,001 & 1815,2 & 19,0 & 1825,8 & 18,9 & 1820,7 & 10,4 & 100,3 \\
\hline GU-403-123 & 41200416 & 0,66 & 4,969 & 0,061 & 0,3272 & 0,0039 & 0,97 & 0,110 & 0,001 & 1802,2 & 19,2 & 1824,6 & 18,9 & 1814,0 & 10,4 & 100,7 \\
\hline GU-403-123 & 5200416 & 0,76 & 4,829 & 0,058 & 0,3200 & 0,0038 & 0,99 & 0,095 & 0,001 & 1789,6 & 18,5 & 1789,9 & 18,4 & 1789,9 & 10 & 100 \\
\hline GU-403-123 & 6200416 & 0,7 & 5,060 & 0,061 & 0,3331 & 0,0039 & 0,99 & 0,054 & 0,001 & 1801,8 & 18,6 & 1853,5 & 19,0 & 1829,5 & 10,2 & 101,5 \\
\hline GU-403-123 & 7200416 & 0,88 & 4,959 & 0,059 & 0,3249 & 0,0038 & 0,99 & 0,085 & 0,001 & 1810,8 & 18,6 & 1813,6 & 18,6 & 1812,4 & 10,1 & 100,1 \\
\hline GU-403-123 & 8200416 & 0,86 & 5,059 & 0,060 & 0,3321 & 0,0039 & 0,99 & 0,077 & 0,001 & 1807,2 & 18,5 & 1848,5 & 18,9 & 1829,3 & 10,1 & 101,2 \\
\hline GU-403-123 & 9200416 & 0,63 & 4,916 & 0,059 & 0,3248 & 0,0038 & 0,99 & 0,094 & 0,001 & 1795,0 & 18,6 & 1813,2 & 18,6 & 1804,9 & 10,1 & 100,6 \\
\hline GU-403-123 & 10200416 & 0,69 & 4,944 & 0,059 & 0,3256 & 0,0038 & 0,99 & 0,094 & 0,001 & 1801,3 & 18,6 & 1816,8 & 18,7 & 1809,8 & 10,1 & 100,5 \\
\hline GU-403-123 & 11200416 & 0,64 & 5,361 & 0,064 & 0,3393 & 0,0040 & 0,99 & 0,111 & 0,001 & 1873,3 & 18,4 & 1883,3 & 19,2 & 1878,7 & 10,2 & 100,3 \\
\hline GU-403-123 & 12200416 & 0,59 & 5,013 & 0,059 & 0,3280 & 0,0039 & 0,99 & 0,096 & 0,001 & 1812,8 & 18,4 & 1828,8 & 18,7 & 1821,4 & 10 & 100,5 \\
\hline GU-403-123 & 16200416 & 0,29 & 4,914 & 0,058 & 0,3242 & 0,0038 & 0,99 & 0,111 & 0,001 & 1798,1 & 18,5 & 1810,1 & 18,5 & 1804,6 & 10 & 100,4 \\
\hline
\end{tabular}


Petrografía, geoquímica y geocronología U/Pb en circones de rocas ígneas y metamórficas a lo largo del Río Cuiarí en el sur del Departamento de Guainía, Colombia

Continuación ANEXO

\begin{tabular}{|c|c|c|c|c|c|c|c|c|c|c|c|c|c|c|c|c|}
\hline \multirow[b]{2}{*}{ Muestra } & \multirow[b]{2}{*}{ Analysis_\# } & \multicolumn{10}{|c|}{ Relaciones } & \multicolumn{5}{|c|}{ Edades } \\
\hline & & $\mathrm{Th} / \mathrm{U}$ & $207 / 235$ & $\begin{array}{l}1 \sigma \\
\text { err }\end{array}$ & $206 / 238$ & $1 \sigma \mathrm{err}$ & rho & $207 / 206$ & $\begin{array}{l}1 \sigma \\
\text { err }\end{array}$ & $207 / 206$ & $1 \sigma$ err & $206 / 238$ & $\begin{array}{c}1 \sigma \\
\text { err }\end{array}$ & $207 / 235$ & $\begin{array}{c}1 \sigma \\
\text { err }\end{array}$ & $\begin{array}{c}\text { Conc } \\
\%\end{array}$ \\
\hline GU-403-123 & 17200416 & 0,77 & 1,689 & 0,021 & 0,1691 & 0,0020 & 0,97 & 0,111 & 0,001 & 999,1 & 21,4 & 1006,9 & 11,0 & 1004,5 & 7,8 & 100,5 \\
\hline GU-403-123 & 19200416 & 0,23 & 3,386 & 0,040 & 0,2614 & 0,0031 & 0,99 & 0,111 & 0,001 & 1506,9 & 19,2 & 1496,8 & 15,7 & 1501,0 & 9,3 & 99,6 \\
\hline GU-403-123 & 20200416 & 0,78 & 4,935 & 0,059 & 0,3245 & 0,0038 & 0,99 & 0,078 & 0,001 & 1804,3 & 18,5 & 1811,6 & 18,5 & 1808,3 & 10 & 100,2 \\
\hline GU-403-123 & 23200416 & 0,52 & 4,830 & 0,058 & 0,3183 & 0,0037 & 0,98 & 0,073 & 0,001 & 1800,2 & 18,8 & 1781,4 & 18,3 & 1790,2 & 10,1 & 99,4 \\
\hline GU-403-123 & 28200416 & 0,57 & 4,896 & 0,058 & 0,3244 & 0,0038 & 0,98 & 0,110 & 0,001 & 1790,3 & 18,7 & 1811,4 & 18,5 & 1801,7 & 10 & 100,6 \\
\hline GU-403-123 & 30200416 & 0,33 & 5,002 & 0,060 & 0,3319 & 0,0039 & 0,98 & 0,108 & 0,001 & 1787,9 & 18,8 & 1847,5 & 18,8 & 1819,7 & 10,1 & 101,8 \\
\hline GU-403-123 & 33200416 & 0,79 & 4,934 & 0,059 & 0,3255 & 0,0038 & 0,98 & 0,102 & 0,001 & 1798,4 & 18,9 & 1816,4 & 18,5 & 1808,1 & 10,1 & 100,5 \\
\hline GU-403-123 & 34200416 & 0,23 & 5,113 & 0,061 & 0,3307 & 0,0039 & 0,98 & 0,099 & 0,001 & 1834,2 & 18,7 & 1841,9 & 18,7 & 1838,3 & 10,1 & 100,2 \\
\hline GU-403-123 & 38200416 & 0,66 & 4,923 & 0,059 & 0,3250 & 0,0038 & 0,97 & 0,078 & 0,001 & 1797,2 & 19,2 & 1814,1 & 18,5 & 1806,3 & 10,2 & 100,5 \\
\hline GU-403-123 & 39200416 & 1,03 & 4,856 & 0,059 & 0,3210 & 0,0038 & 0,97 & 0,048 & 0,001 & 1795,0 & 19,2 & 1794,5 & 18,3 & 1794,7 & 10,2 & 100 \\
\hline GU-403-123 & 41200416 & 0,6 & 4,936 & 0,060 & 0,3242 & 0,0038 & 0,96 & 0,110 & 0,001 & 1806,7 & 19,5 & 1810,1 & 18,4 & 1808,5 & 10,3 & 100,1 \\
\hline GU-403-121 & 5190416 & 0,49 & 3,580 & 0,042 & 0,2675 & 0,0031 & 0,99 & 0,097 & 0,001 & 1568,3 & 19,1 & 1528,3 & 15,8 & 1545,0 & 9,4 & 98,5 \\
\hline GU-403-121 & 6190416 & 0,57 & 4,757 & 0,056 & 0,3177 & 0,0037 & 0,98 & 0,109 & 0,001 & 1776,1 & 18,7 & 1778,5 & 18,1 & 1777,3 & 9,9 & 100,1 \\
\hline GU-403-121 & 7190416 & 0,66 & 4,797 & 0,057 & 0,3174 & 0,0037 & 0,98 & 0,110 & 0,001 & 1793,1 & 18,7 & 1777,0 & 18,1 & 1784,3 & 10,0 & 99,5 \\
\hline GU-403-121 & 8190416 & 0,75 & 4,969 & 0,059 & 0,3291 & 0,0038 & 0,98 & 0,110 & 0,001 & 1791,5 & 18,8 & 1833,9 & 18,6 & 1814,0 & 10,1 & 101,3 \\
\hline GU-403-121 & 9190416 & 0,26 & 3,524 & 0,042 & 0,2724 & 0,0032 & 0,99 & 0,094 & 0,001 & 1505,3 & 19,2 & 1552,7 & 16,1 & 1532,6 & 9,3 & 101,8 \\
\hline GU-403-121 & 10190416 & 0,51 & 0,198 & 0,003 & 0,0269 & 0,0003 & 0,88 & 0,053 & 0,001 & 345,4 & 27,6 & 171,1 & 2,0 & 183,4 & 2,3 & 53,1 \\
\hline GU-403-121 & 11190416 & 0,66 & 0,176 & 0,002 & 0,0251 & 0,0003 & 0,87 & 0,051 & 0,001 & 236,6 & 27,3 & 159,9 & 1,9 & 164,8 & 2,0 & 69,7 \\
\hline GU-403-121 & 12190416 & 1,53 & 3,359 & 0,040 & 0,2365 & 0,0028 & 0,98 & 0,103 & 0,001 & 1679,1 & 19,0 & 1368,6 & 14,4 & 1494,9 & 9,3 & 89,0 \\
\hline GU-403-121 & 16190416 & 1,03 & 4,724 & 0,057 & 0,3174 & 0,0037 & 0,97 & 0,108 & 0,001 & 1765,0 & 19,1 & 1777,1 & 18,2 & 1771,5 & 10,2 & 100,4 \\
\hline GU-403-121 & 17190416 & 0,76 & 4,679 & 0,057 & 0,3205 & 0,0038 & 0,97 & 0,106 & 0,001 & 1729,6 & 19,2 & 1792,4 & 18,4 & 1763,5 & 10,1 & 102,0 \\
\hline GU-403-121 & 18190416 & 1,68 & 3,620 & 0,043 & 0,2672 & 0,0031 & 0,98 & 0,098 & 0,001 & 1591,8 & 19,3 & 1526,6 & 15,9 & 1554,0 & 9,6 & 97,6 \\
\hline GU-403-121 & 20190416 & 0,26 & 2,306 & 0,028 & 0,1800 & 0,0021 & 0,98 & 0,093 & 0,001 & 1486,2 & 19,6 & 1067,0 & 11,5 & 1214,1 & 8,5 & 81,7 \\
\hline GU-403-121 & 22190416 & 0,97 & 3,832 & 0,046 & 0,2794 & 0,0033 & 0,97 & 0,099 & 0,001 & 1614,0 & 19,3 & 1588,5 & 16,6 & 1599,4 & 9,7 & 99,1 \\
\hline GU-403-121 & 27190416 & 0,53 & 1,869 & 0,023 & 0,1807 & 0,0021 & 0,95 & 0,075 & 0,001 & 1068,6 & 21,8 & 1071,0 & 11,7 & 1070,2 & 8,3 & 100,1 \\
\hline GU-403-121 & 28190416 & 0,72 & 1,558 & 0,021 & 0,1534 & 0,0018 & 0,89 & 0,074 & 0,001 & 1033,0 & 23,9 & 919,9 & 10,2 & 953,8 & 8,3 & 92,3 \\
\hline GU-403-121 & 32190416 & 2,08 & 3,378 & 0,042 & 0,2475 & 0,0029 & 0,96 & 0,099 & 0,001 & 1605,2 & 19,8 & 1425,6 & 15,2 & 1499,2 & 9,7 & 93,4 \\
\hline GU-403-121 & 33190416 & 0,44 & 3,225 & 0,040 & 0,2390 & 0,0028 & 0,96 & 0,098 & 0,001 & 1583,6 & 19,7 & 1381,7 & 14,7 & 1463,1 & 9,5 & 92,4 \\
\hline GU-403-121 & 34190416 & 3,12 & 3,476 & 0,043 & 0,2629 & 0,0031 & 0,96 & 0,096 & 0,001 & 1546,2 & 19,9 & 1504,6 & 15,9 & 1521,9 & 9,7 & 98,4 \\
\hline GU-403-121 & 38190416 & 0,52 & 3,382 & 0,042 & 0,2418 & 0,0029 & 0,96 & 0,101 & 0,001 & 1651,2 & 19,7 & 1396,0 & 14,9 & 1500,3 & 9,7 & 90,9 \\
\hline GU-403-121 & 40190416 & 2,10 & 2,837 & 0,036 & 0,2041 & 0,0024 & 0,95 & 0,101 & 0,001 & 1639,4 & 20,0 & 1197,2 & 13,0 & 1365,3 & 9,4 & 83,3 \\
\hline GU-403-121 & 41190416 & 1,77 & 3,465 & 0,043 & 0,2517 & 0,0030 & 0,95 & 0,100 & 0,001 & 1621,3 & 20,1 & 1447,4 & 15,5 & 1519,3 & 9,9 & 93,7 \\
\hline
\end{tabular}

